Georgia State University

ScholarWorks @ Georgia State University

$12-2009$

\title{
The Cross Race Effect: The Influence of Stereotypicality on Memory Errors
}

Leslie Riddick Knuycky

Georgia State University

\section{Recommended Citation}

Knuycky, Leslie Riddick, "The Cross Race Effect: The Influence of Stereotypicality on Memory Errors." Thesis, Georgia State University, 2009. doi: https://doi.org/10.57709/1229455

This Thesis is brought to you for free and open access by the Department of Psychology at ScholarWorks @ Georgia State University. It has been accepted for inclusion in Psychology Theses by an authorized administrator of ScholarWorks@ Georgia State University. For more information, please contact scholarworks@gsu.edu. 
THE CROSS RACE EFFECT: THE INFLUENCE OF STEREOTYPICALITY ON MEMORY

ERRORS

By

\title{
LESLIE RIDDICK KNUYCKY
}

Under the Direction of Heather Kleider

\begin{abstract}
In eyewitness identification cases, suspect misidentification is the leading factor attributed to wrongful convictions (Scheck, Neufeld, \& Dwyer, 2000), thus, it is of applied importance to identify factors that contribute to the false recollection of faces. One potential factor addressed in the current study was whether face memory and subsequent identification for other-race-faces is biased by the degree to which a target face posses facial features associated with ethnic identity. Individual differences in level of processing (global, local) and prejudice were tested as potential mechanisms contributing to biased judgments. In Experiment $1 \mathrm{a}$ standard face recognition task revealed that prejudice, level of processing, and face-type interacted to predict recognition bias. In Experiment 2 results showed that positive misidentifications (i.e., choosing an incorrect foil) were more likely when a stereotypical versus non-stereotypical Black actor was witnessed committing the crime. Results are discussed in
\end{abstract}


terms of theoretical and practical implications.

INDEX WORDS: $\quad$ Cross-race effect, Face recognition, Face identification, Face memory, Stereotypicality 


\title{
THE CROSS RACE EFFECT: THE INFLUENCE OF STEREOTYPICALITY ON MEMORY ERRORS
}

by

\section{LESLIE RIDDICK KNUYCKY}

A Thesis Submitted in Partial Fulfillment of the Requirements for the Degree of

\author{
Master of Arts \\ in the College of Arts and Sciences \\ Georgia State University
}


Copyright by

Leslie Riddick Knuycky 2009 
THE CROSS RACE EFFECT: THE INFLUENCE OF STEREOTYPICALITY ON MEMORY

\title{
ERRORS
}

by

\section{LESLIE RIDDICK KNUYCKY}

\author{
Committee Chair: $\quad$ Dr. Heather Kleider \\ Committee: Dr. Tracie Stewart \\ Dr. David Washburn
}

Electronic Version Approved:

Office of Graduate Studies

College of Arts and Sciences

Georgia State University

December 2009 


\section{TABLE OF CONTENTS}

\section{CHAPTER}

1. INTRODUCTION 1

Overview 2

The Cross-Race Effect and Facial Features 2

Scripts, Schemas and Stereotypes 5

The Criminal Stereotype $\quad 8$

$\begin{array}{ll}\text { Stereotypes and Memory } & 10\end{array}$

$\begin{array}{ll}\text { Lineups } & 12\end{array}$

The Present Study 13

$\begin{array}{lc}\text { Hypotheses } & 16\end{array}$

2. EXPERIMENT 1

$\begin{array}{lr}\text { Overview and Analyses } & 17\end{array}$

$\begin{array}{ll}\text { Participants } & 17\end{array}$

$\begin{array}{lr}\text { Materials } & 18\end{array}$

$\begin{array}{lr}\text { Processing Focus-Type Task } & 18\end{array}$

$\begin{array}{ll}\text { Face Recognition } & 18\end{array}$

$\begin{array}{ll}\text { Pilot Test } & 18\end{array}$

Present Study 19

$\begin{array}{ll}\text { Individual Prejudice Survey } & 20\end{array}$

$\begin{array}{ll}\text { Procedure } & 21\end{array}$

$\begin{array}{ll}\text { Processing Focus-Type Task } & 21\end{array}$ 
Face Recognition Task $\quad 21$

$\begin{array}{ll}\text { Encoding phase } & 21\end{array}$

$\begin{array}{ll}\text { Distracter phase } & 21\end{array}$

$\begin{array}{ll}\text { Recognition phase } & 21\end{array}$

Individual Prejudice Survey Task 22

$\begin{array}{ll}\text { Results } & 22\end{array}$

Processing Focus-Type: Global versus Local 22

Individual Prejudice: High versus Low 23

Explanation of d' and C 23

$\begin{array}{ll}\text { Hypotheses and Analyses } & 24\end{array}$

$\begin{array}{ll}\text { Preliminary Analyses } & 24\end{array}$

$\begin{array}{ll}\text { Primary Analyses } & 24\end{array}$

Hits 25

$\begin{array}{ll}\text { False Alarms } & 25\end{array}$

D’ (Accuracy) 26

$\begin{array}{ll}\text { C (Criterion) } & 26\end{array}$

$\begin{array}{ll}\text { Discussion } & 27\end{array}$

3. EXPERIMENT 2

$\begin{array}{ll}\text { Overview and Analyses } & 29\end{array}$

$\begin{array}{ll}\text { Participants } & 30\end{array}$

$\begin{array}{ll}\text { Materials } & 30\end{array}$

Face Identification Task 30 
$\begin{array}{ll}\text { Identification phase } & 31\end{array}$

$\begin{array}{ll}\text { Procedure } & 32\end{array}$

Processing Focus-Type Task 32

Face Identification Task 32

$\begin{array}{ll}\text { Encoding phase } & 32\end{array}$

Distracter phase $\quad 32$

Identification phase $\quad 32$

Individual Prejudice Survey Task 33

$\begin{array}{ll}\text { Results } & 33\end{array}$

Processing Focus-Type: Global versus Local 33

Individual Prejudice: High versus Low 34

$\begin{array}{ll}\text { Hypotheses and Analyses } & 34\end{array}$

Manipulation Check 34

Prediction 1- Choosing Behavior 34

Prediction 2- Accuracy of Lineup Decisions 35

Prediction 3- Stereotypicality of Lineup Identifications 36

Prediction 4- Confidence in Lineup Decisions 37

$\begin{array}{ll}\text { Discussion } & 39\end{array}$

4. GENERAL DISCUSSION 41

Theoretical Implications $\quad 44$

Practical Implications $\quad 45$ 
Limitations and Future Directions $\quad 46$

$\begin{array}{ll}\text { Conclusion } & 47\end{array}$

$\begin{array}{ll}\text { REFERENCES } & 48\end{array}$

APPENDICES

Table 1. Accuracy Rate Descriptives $\quad 54$

Figure 1. Processing Focus-Type Stimuli 55

Figure 2. Experiment 1

Figure 3. Experiment 2 Prediction $1 \quad 57$

Figure 4. Experiment 2 Prediction 2

Figure 5. Experiment 2 Prediction 3

Figure 6. Experiment 2 Prediction 4a 60

Figure 7. Experiment 2 Prediction 4b 61 


\section{CHAPTER ONE.}

\section{INTRODUCTION}

Face recognition is a skill human infants demonstrate shortly after birth (Slater \& Quinn, 2001), suggesting that distinguishing friend from foe is evolutionarily adaptive. However, innateness does not equate to simplicity. Face recognition and/or identification can be a difficult task with myriad factors that contribute to error (e.g., stress, weapon focus, and exposure duration) and potentially result in devastating consequences. Thus, my aim in this project is to investigate whether facial features typically associated with Black people bias face categorization and ultimately influence recognition and identification accuracy of other-race faces.

One consequence of face misrecognition is exemplified by Antonio Beaver's story wherein one man became a victim of the justice system after a misidentification made by a witness. On August 15, 1996, a 26-year-old Caucasian woman was attacked with a screwdriver by an African American man in a St. Louis parking lot. After being stabbed, the woman fled the scene to call police while the perpetrator drove off with her car. Six days after the incident the woman was called to the police station to make a lineup identification of her attacker. The victim identified Beaver. In April of 1997, regardless of evidence exculpating the defendant, the victim's memory of the event and of the perpetrator was sufficient to warrant a conviction of first-degree robbery for Beaver with an 18-year sentence. In 2006, The Innocence Project accepted Beaver's case and convinced the state to test the DNA of a blood swab that had been recovered from the victim's car. The DNA results cleared Beaver who was exonerated on March 29, 2007. Antonio Beaver spent 10 years of his life in prison because the victim identified him as the perpetrator of a crime he did not commit. Unfortunately, Beaver's incident is not uncommon. 
It is cases like that of Antonio Beaver's that have inspired the founders of the Innocence Project to make it their mission to help to free prisoners who could be proven innocent through DNA testing. In the 16 years since the start of the project, 212 people have been exonerated, 15 of whom had served time on death row. Multiple factors are listed as contributing to these former prisoner’s wrongful convictions including: unreliable/limited science, misinformation from informants/snitches, forensic science misconduct, false confessions/admissions, government misconduct, poor defense, and eyewitness misidentifications. In over $75 \%$ of the cases eyewitness misidentifications are the most frequent cause (and often the sole cause) cited for the wrongful convictions (The Innocence Project, 2008).

\section{Overview}

In the present study I will investigate how the stereotypicality of Black faces affect crossrace face recognition. Specifically, I will investigate (1) for White participants, whether recognition accuracy differs between Black faces with more or less stereotypical features (2) and whether the activation of the criminal stereotype differentially affects the observed face recognition pattern. Throughout Chapter 1 , I will review the cross-race effect and how face-type may influence recognition memory as well as the effects scripts/schemas and stereotypes have on memory more generally. Finally, I will discuss lineup procedures and explain the stages in which stereotype activation may lead to lineup misidentifications.

\section{The Cross-Race Effect and Facial Features}

People are generally better at recognizing a person of their own race than a person of another race, a phenomenon known as the cross-race effect (CRE). The CRE is one of the most 
reliably replicated findings in face perception research (Anthony, Copper, Mullen, 1992) and has consistently been found to contribute significantly to face recognition errors. In a meta-analysis of 39 articles on the CRE, Meissner and Brigham (2001) found that mistaken identifications were 1.56 times greater for cross-race faces than same-race faces. The most common error for other-race identifications is mistakenly recognizing a new (unseen) face as previously seen, leading to false positive identifications.

Whereas there are an abundance of models to explain the CRE (see Meissner \& Bringham, 2001; Sporer, 2001), two dominant theories have been proposed. The perceptualexpertise theory posits that the CRE is due to a lack of experience with other-race faces resulting in a tendency to process them more feature-based and less holistically (Michel, Rossion, Han, Chung, \& Caldara, 2006). Conversely, the social-categorization theory suggests that people are motivated to process faces from their in-group more deeply than faces from their out-group (Rodin, 1987). Regardless of mechanism each theory currently implies that there is a categorical divide between Black and White faces suggesting that any Black face is as likely to be misrecognized as the next. More recently, researchers have found that people appear to have subcategories for faces which are defined based on the degree to which a face possesses features commonly associated with an ethnic group (i.e., stereotypical facial features versus nonstereotypical facial features). Specifically, Blair, Judd, Sadler, and Jenkins (2002) found that participants were more likely to associate faces exhibiting strong stereotypical versus nonstereotypical features with a negative African American stereotype (i.e., grew up in inner-city Detroit, was attending college on a basketball scholarship, has failed several classes, had been involved in fights on the basketball court, and was waiting to talk with his coach about a drug charge). In a follow-up study, Blair, Judd, and Fallman (2004b) directed participants to make 
face/description associations while avoiding the use of race or features. Results revealed that participants were able to make less stereotypical associations based on race; however, they continued to make stereotypical associations based on features. The authors suggested that the influence of the subcategories on participants' association decisions was automatic being that they were able to consciously avoid the use of the broader category of race. In a more applied study, Blair, Judd, and Chapleau (2004a) found that these subcategories were positively correlated with convicted felons' prison sentences; however, there was no difference in prison sentence for White and Black felons. Specifically, White and Black felons received equal prison sentences across category, but Black and White prisoners with stereotypical faces received significantly longer sentences than Black and White prisoners with non-stereotypical faces. In a related study, Livingston and Brewer (2002) presented various face primes (stereotypical Black, non-stereotypical Black, White) followed by target nouns that participants were to classify as either good or bad. The results revealed that stereotypical Black face primes facilitated participants' responses to negative nous and inhibited their responses to positive nouns. There was no difference in participants' responses to the nouns following the non-stereotypical Black versus White face primes. The authors concluded that it is not category membership that people automatically respond to, but instead perceptual cues (i.e. stereotypicality).

Taken together, it is clear that there are subcategories, above and beyond Black and White, which have a profound influence on judgments and decision making. Furthermore, these studies suggest that more typical Black facial features are most representative of the prototypical Black face known to be linked with the criminal stereotype (which will be described in detail below) whereas less typical Black facial features are most representative of the White face. Thus, stereotypicality could be an influencing factor in the cross-race effect. For example, White 
people may consider Black faces with less typical Black features to be part of their in-group and/or process them more holistically making non-stereotypical faces easier to identify. Conversely, they may view Black faces with more typical Black features as part of their outgroup and/or process them more feature-based, thereby increasing recognition difficulty. This projection would suggest that gradations in in-group/out-group status and/or facial feature experience impact judgments and that the proposed categorical divide in the two-category theories is too simplistic. Alternatively, these theories would be supported if any Black face, regardless of face-type, is misidentified more than White faces as evidenced by false alarm rate.

\section{Scripts, Schemas, and Stereotypes}

A person's knowledge regarding what is involved in a particular experience is a schema. Previous experiences shape how new information is interpreted and organized in memory. Organizing knowledge into schemas and stereotypes that reflect one's expectations for events or people increases general cognitive efficiency (Goldstein, 2005). Schema theorists (Alba \& Hasher, 1983) contend that schemas can significantly reshape memory through the four central encoding processes: selection, abstraction, interpretation, and integration. Schemas promote the subconscious selection and modification of incoming information in an effort to create “coherent, unified, expectation-confirming, and knowledge-consistent representations of an experience,” (Alba \& Hasher, 1983; pg. 203). People use schemas quickly to understand an event and to determine how to react while expending few cognitive resources. In short, schemas are developed from past experiences to understand the present and provide expectations for future experiences. Tuckey and Brewer (2003) found that after witnessing a mock bank robbery participants' memory for the event was influenced by their knowledge regarding the typical 
happenings such that the presentation of an ambiguous scene versus unambiguous scene led to more schema-consistent memory intrusions.

Scripts are schemas for a particular type of event, and include information about props, roles and rules regarding the chronology of events within the script (Fiske, 2004). For example, Holst and Pezdek (1992) found that people expect different actions to take place during various robberies (bank, convenience store, and mugging) regardless of one's personal experience with such an event. Specifically, the authors found that while almost all participants agreed that the perpetrator would demand money in a convenience store or bank robbery, only $32 \%$ of the participants suggested that this action would take place during a mugging. Like schemas, scripts can be so powerful that people witnessing an event later recall script-relevant actions that were not presented in the original event. Holst and Pezdek (1992) found that when participants were questioned one week after hearing eyewitness testimony from a mock trial recording they recalled and recognized a significant number of script-relevant statements that were not actually presented.

Whereas scripts are organizational constructs for events, stereotypes are organizational constructs for people. Stereotypes may be related to gender (e.g., women are nurturing), profession (e.g., engineers are geeks), or ethnicity (e.g., Asian people are good at math), and may include positive or negative characteristics. In many instances stereotypes are activated automatically, even when people try to avoid their use. For example, Payne, Lambert, and Jacoby (2002) presented participants with a prime consisting of either a Black or a White face, followed by a picture of either a tool or a weapon and then asked participants to identify the object. Participants primed with the Black face more accurately identified the weapon and misidentified the tool, a tendency that persisted regardless of instructions to avoid using race as a 
cue. A follow-up study revealed that participants were immediately aware of their object classification errors and were able to provide the correct classification when given a second opportunity, but were unable to suppress the erroneous classification initially (Payne, Shimizu, \& Jacoby, 2005). The authors suggested that the robustness of activated stereotypes make it difficult to suppress rapid response decisions. In more deliberative judgments, stereotypes can also promote event-memory errors when the initial episode is less vivid after a time delay. In a study by Kleider, Pezdek, Goldinger, and Kirk (2008), participants viewed a homemaker and a handyman working in a home performing both stereotypical (handyman hammering nails) and atypical (handyman baking cookies) actions. Two days later, participants were more likely to misattribute actions to the stereotypical actor as opposed to the atypical actor witnessed performing the action. The authors suggested that people rely on stereotypes to determine the source of information when episodic memory is weak. Furthermore, Jones and Kaplan (2003) found that when mock-jurors were asked to make verdict decisions for perpetrators accused of committing stereotype-consistent (i.e., Black man committing a blue-collar crime like grandtheft auto or a White man committing a white-collar crime like embezzlement) versus stereotype-inconsistent crimes participants rendered more guilty verdicts, gave longer sentences, held the perpetrator more responsible for the crime, and were more confident in their decisions. The authors theorized that stereotype-confirming information elicits less of a search for disconfirming facts. Furthermore, the efficiency of using stereotypes makes them especially appealing in situations that are cognitively taxing (Kleider, Knuycky, Cavrak, \& Myers, 2010). Taken together these findings suggest that stereotypes can influence judgments and memory for event actions as well as the people in the events. 


\section{The Criminal Stereotype}

One established stereotype is the association between the Black male and the tendency towards violence and crime (MacLin \& Herra, 2006; Duncan, 1976). For example, Duncan (1976) showed participants a video of two people discussing a problem. The discussion concluded with one actor shoving the other. Duncan found that when the instigator was Black, participants labeled the behavior as violent, however, when the instigator was White, participants labeled the behavior as nonviolent. Similarly, Sager and Schofield (1980) revealed that this tendency persisted for Black participants too. The researchers suggested that this finding was the result of over-learned stereotypes from one's culture that became automatic even when not endorsed.

The criminal association has also been established in eyewitness situations. For example, Oliver (1999) showed participants a 30-minute news clip wherein two wanted posters were displayed for 10 seconds each. The posters depicted perpetrators of one violent and one nonviolent crime (Black and White counterbalanced). The participants tried to identify the violent criminal among foils both immediately and again three months later. The accuracy of the immediate identifications was not affected by the race of the perpetrator. However, over time, participants that originally saw a White suspect paired with the violent act were increasingly likely to erroneously recall a black suspect. In a follow-up study, Oliver \& Fonash (2002) decreased the time delay between witnessing the perpetrator and completing the identification task. Participants read crime briefs coupled with a photograph of the suspect (both Black and White). After a 20-minute delay, participants were asked to identify which of 10 photos were featured in the previously read crime briefs. Of the 10 presented photos only 4 were suspects (6 were filler, 3 Black, and 3 White). Participants were significantly more likely to misidentify a 
Black foil than a White foil as featured in the violent crime stories. The authors found no difference in identifications for the nonviolent stories. Taken together, these studies exemplify the strength of the "Black-man-as-criminal" stereotype; however, some researchers suggest that there may be more to looking criminal than just being Black.

Is any Black man considered equally as criminal as the next? Researchers asking these types of questions date back as far as 1956 when Secord, Bevan, and Katz (1956) as well as Secord (1959) inquired as to whether the degree to which a Black face was comprised of Caucasoid features would affect stereotyping. The authors found that when participants knew the race of the face they categorized it simply as Black or White and ascribed the "appropriate" stereotypes to the person. However, when participants mistook the Black faces pictured in Black and White photos as being that of a White person they avoided ascribing the same stereotypes. More recent work has continued questioning in this same vein. In a study by Dixon and Maddox (2005) participants watched a news clip embedded with a crime story which depicted either a White, light-skinned Black, medium-skinned Black, or dark-skinned Black perpetrator. The perpetrators' face remained constant while the skin tone was manipulated. Following the newscast, participants completed a memory task and reported news-viewing habits. The results revealed that frequent news viewers were significantly more emotionally concerned about the news story when the perpetrator was a dark-skin Black person versus a White person. Infrequent news viewers reported no difference in emotional concern regardless of the perpetrator depicted. The authors concluded that skin tone was sufficient for causing biased judgments. Such biased judgments appeared again in a recent field study that suggested that the criminal stereotype involves features other than just skin color/tone. Eberhardt, Davies, Purdie-Vaughns, and Johnson (2006) found that Black males rated as more stereotypical were more likely to receive 
the death penalty when on trial for murdering a White victim. Stereotypicality was rated subjectively with more stereotypical features characterized by larger lips, broader nose and darker complexion and less stereotypical features characterized by thinner lips, thinner nose, and lighter complexion. Additionally, Kleider, Cavrak, Knuycky, and Myers (2010) found that in a face recognition study, participants primed “murderer” prior to viewing a series of Black male faces, were more likely falsely to recognize more stereotypical than non-stereotypical faces in a memory test, whereas priming “doctor” did not differentially influence false recognitions. The researchers suggested that the criminal prime led to biased memory for Black faces that were most representative of the stereotypical criminal. It follows from these recent findings that certain face-type (other than color) may be a critical component of the criminal stereotype that could influence memory for faces.

\section{Stereotypes and Memory}

As chronicled above, research to date has established that facial features influence decision making (Blair et al., 2002; Blair et al., 2004b). Additional researchers (Blair et al., 2004a; Eberhardt et al., 2006; \& Kleider et al., 2010) have demonstrated that stereotypical faces are associated with the criminal stereotype. However, what remains unknown is the effect stereotypicality has on non-Black person’s memory for a criminal perpetrator.

Although the use of schemas and stereotypes aide recollection, they also may be a precursor to biased face memory. According to schema theory, information is encoded in memory based on prior knowledge, activation of an existing schema, and "the importance of the incoming information with respect to the schema” (Alba \& Hasher, 1983; pg. 205). With a 
working schema that becomes activated, relevant information is easily encoded; however, other information is either distorted or discarded in order to fit the schema.

Relevant to the current study, activated schemas and stereotypes could alter memory for a witnessed perpetrator at different phases of processing. Though the specific location of potential memory errors is not the focus of this experiment, the phases are explained in an effort to facilitate the reader's comprehension of the effects of schema/stereotypes on memory. First, regularly activated stereotypes such as “criminals are Black men with more typical features,” could distort the stimuli selected for encoding. Next is abstraction, which is the process of encoding the meaning-based representation (or 'gist') of the event. It is at this stage that memorial detail is lost and the overall meaning is retained. For example, an eyewitness may remember an event summary such as, “a Black man committed grand-theft auto” whereas the specifics regarding the man’s appearance are forgotten. In the third process, interpretation, schematic knowledge influences the construction of the final memory trace because inferences are used to encode explicitly presented information. Interpretation errors involve adding information to a memory. The eyewitness may interpret the perpetrator to be a "typical" bluecollar criminal, thus, adding stereotypically Black features to the memory of the perpetrator that were not actually present. Finally, integration is the process by which specific incoming information is stored within a larger semantic whole. Thus, the memory for the witnessed crime will be integrated with other crime-relevant information. It is here that we are likely to confuse our scripts/stereotypes with our actual memories (e.g., Kleider et al., 2008). All of the aforementioned components of schema theory (selection, abstraction, interpretation, and integration) can lead to distortions in memory when the original memorial event is ambiguous or vague. An eyewitness's memory is notoriously weak and thus ambiguous (see Haber \& Haber, 
2000). This begs the question of what happens when an eyewitness with a vague memory for a perpetrator is asked to make a lineup identification.

\section{Lineups}

The eyewitness memory literature shows that lineup configuration, (i.e., sequential or simultaneous) has a large impact on whether a perpetrator is accurately identified. Simultaneous lineups present mug shots in a side-by-side configuration, which encourages witnesses to use a relative comparative strategy. In the relative comparative strategy each mug shot is scanned and compared to each other mug shot in an effort to determine which mug shot most represents the perpetrator witnessed committing the crime. Conversely, with sequential lineup eyewitnesses make identifications by attempting to match a single mug shot to the remembered perpetrator (Wells, 1984). This is often referred to as an absolute judgment strategy. Absolute judgments lead to a conservative criterion shift wherein fewer identifications (either accurate or inaccurate) are made (Meissner, Tredoux, Parker, \& MacLin, 2005). Regardless of lineup presentation, when witnesses make a cross-race identification, they tend to rely on a relative, as opposed to an absolute, decision strategy (Smith, Stinson, \& Prosser, 2004). That is, they were more likely to report that they chose the person that looked most like the perpetrator as opposed to choosing the person that specifically matched their recollection. Use of a relative decision strategy may cause the more stereotypical-featured criminal to appear the most familiar due to the process of integration. Specifically, integration involves storing an actual memory with other schemaconsistent information. Thus, memory for the perpetrator may be confused with stereotypes regarding the 'typical' Black criminal. 


\section{The Present Study}

My aim in the present study is to examine how stereotypicality of Black facial features influences White persons' memory for faces. In addition to contributing to the cross-race theory there are practical reasons why this is a valuable investigation to undertake. Specifically, when making lineup identifications, eyewitnesses are often confident even when making a misidentification suggesting that confidence and accuracy is not necessarily correlated (Wells \& Murray, 1984). Unfortunately juries are not aware of this disconnect between an eyewitnesses confidence and accuracy and as a result incorrect eyewitness identifications continue to be the number one factor leading to wrongful convictions (Huff, Ratner, \& Sagarian, 1986). Therefore, it is essential to examine the circumstances behind such incorrect identifications.

In the present investigation, the effects of stereotypicality on memory for faces will be explored in a two-part study. Individual differences in processing focus-type (global versus local) and prejudice will be assessed in an effort to better understand the mechanisms underlying recognition accuracy and bias in cross-race face recognition. Global processors focus attention to the larger picture while local processors focus attention to the featural detail. Global, compared to local, processors are expected to have the advantage in face recognition since a holistic processing-style (i.e., processing the entire face as a whole) is related to superior same-race face recognition (Michel, et al., 2006). Furthermore, individual prejudice is predicted to affect face recognition bias. Specifically, high prejudice likely reduces motivation to individuate and instead is related to categorizing out-group members. An ubiquitous consequence of categorization is homogenization (Fiske, 2004) or the 'they all look alike’ effect. Consequently, high individual prejudice should result in misplaced familiarity and false-positive identifications (i.e., identifying 
an innocent foil). Conversely, a low level of prejudice should increase motivation to individuate cross-race faces a factor shown to eliminate the CRE (Hugenberg, Miller, \& Claypool, 2007).

The goal for Experiment 1 is to determine whether the CRE automatically (i.e., without cues related to ethnic stereotypes) affects face recognition for all Black faces equally or if stereotypical faces, as opposed to non-stereotypical faces, are the more likely target of recognition bias. Participants will identify faces presented in a traditional face recognition paradigm. Specifically, White participants’ Black-face-recognition will be indexed by accuracy and criterion.

The goal for Experiment 2 is to assess the effects of stereotypicality on the CRE in a more applied context. Specifically, [potential outcome 1], if (a) recognition accuracy is decreased and/or (b) criterion scores are more liberal for stereotypical than non-stereotypical Black faces in Experiment 1, then in Experiment 2 I will investigate the consequences of such memory biases on lineup identifications. I expect that more stereotypical faces presented in a lineup are at greater risk for false-positive misidentifications than non-stereotypical faces because of (a) reduced recognition accuracy and/or (b) a more liberal recognition criterion resulting in a tendency to readily identify stereotypical faces as previously seen.

Alternatively [potential outcome 2], if participants (a) recognition rates and/or (b) criterion scores are equivalent for stereotypical and non-stereotypical faces in Experiment 1, then in Experiment 2 I will test whether, after activating the criminal stereotype, stereotypicality affects cross-race identifications. In this case, I again expect that stereotypical persons are at greater risk for false-positive misidentifications than non-stereotypical persons. Stereotypical (versus non-stereotypical) faces are often linked to negative stereotypes, thus, when recalling the criminal event for identification purposes a stereotypical face may better fit the role of 
perpetrator than non-stereotypical face. Either outcome 1 or 2 would support the hypothesis that stereotypicality is an influencing factor in cross-race face recognition. However, if outcome 2 results, the implication would be that these perceptual-cues (stereotypicality) do not automatically affect face identification; rather only after stereotype activation, do they bias crossrace face memory.

However, [potential outcome 3], it is possible that both stereotypical and nonstereotypical faces receive similar (a) accuracy rates and (b) criterion scores in Experiment 1 and, all foils are equally misidentified in Experiment 2. This finding (outcome 3) would provide evidence to suggest that the CRE is in fact a "Black and White" issue and that face-type does not affect cross-race face recognition. Only White persons will be recruited as participants in an effort to address these questions.

For Experiment 2, I posit that seeing any Black man commit a race-congruent crime will activate criminal stereotypes causing a more stereotypical/expected person to be misidentified in a subsequent lineup task. However, the contrary could be the case. For example, seeing a perpetrator that does not match the stereotype (a non-stereotypical Black man) may make the event more salient (discordant with one's expectations) and later cause the perpetrator to be more easily identified. However, Oliver’s (1999) findings that Black suspects were mistakenly linked to violent crimes committed by White suspects suggest that more often, when presented with something unexpected, people try to recast their memory to maintain consistency and meet expectations. This is especially true when memory has faded with time; people fill in memory gaps with expectation-consistent event details and/or misremember people performing expected actions (Kleider et al., 2008). 


\section{Hypotheses}

- In Experiment 1, Black face-type (i.e., stereotypicality) will influence face recognition such that White participants will (a) be less accurate and (b) make more liberal (i.e., lax) recognition decisions for faces with stereotypical versus non-stereotypical features as evidenced by hit rate, false alarm rate, accuracy scores and criterion scores.

- In Experiment 2, the indexed stereotypicality of the actor's features will influence subsequent lineup identification such that White participants will (a) make more errors and (b) make more liberal identification decisions after witnessing the stereotypical than the nonstereotypical actor commit a mock-crime. Responses will be evaluated by choosing behavior and accuracy of choice.

- In Experiment 2, faces misidentified in a lineup will posses more stereotypical Black facial features than the actual perpetrator who was witnessed committing the crime.

- In Experiment 2, confidence ratings taken immediately after lineup decisions will be reflective of accuracy for persons making a positive identification (choosing a face) but not for those making a negative identification (choosing not present). 


\section{CHAPTER TWO:}

\section{EXPERIMENT 1}

\section{Overview and Analyses}

Participants completed a total of three tasks in the following order: processing focus-type task, face recognition, and individual prejudice survey. The processing focus-type task required participants to identify a series of stimuli based on the features comprising the figure (local) or the figure comprised by the features (global). The face recognition task was composed of three phases; during the encoding phase participants viewed a series of Black- (stereotypical and nonstereotypical) and White-faces presented in a random sequence via a computer slideshow. After a 15-minute distracter phase, participants completed a face recognition phase. Finally, the Bogardus (1925) Social Distance Scale (SDS) was administered as a measure of individual prejudice. All hit and false alarm data from the face recognition task were entered into a signal detection analyses in order to attain accuracy (d') and criterion (C) scores. Hits, false alarms, d' and C scores were analyzed separately as outcome variables in an ANOVA with processing focus-type (global, local) and prejudice (low, high) as between-subjects variables; face-type (stereotypical, non-stereotypical) was added as a within-subjects variable for the Black face analyses.

\section{Participants}

A total of 22 White (13 female) undergraduate students were recruited from introductory psychology courses at Georgia State University in exchange for course credit. Participants were run in groups of 2 to 8 during experimental sessions. 


\section{Materials}

Processing Focus-Type Task

Processing focus-type was tested using a symbol judgment task similar to the task used by Ward (1982). Four symbols were created including: a large X comprised of 12 small xs (symbol 1) or small +s (symbol 2) and a large + comprised of 12 small xs (symbol 3) or small +s (symbol 4). Separately, two indicator symbols were created and used to focus participant’s attention to the shape within the symbol that they were to categorize (i.e., large or small). Specifically, a large or small circle was presented immediately before a randomly selected symbol. The small circle-indicator directed participants to categorize the small shape while the large circle-indicator directed participants to categorize the large shape. All symbols and indicators were created in white font and presented on a black background. The indicator screen was shown for an indefinite duration advancing to the symbol screen after the spacebar was pressed. The symbol screen was presented for $133 \mathrm{~ms}$ followed by a black mask. Participant response cued the start of the next trial.

The task consisted of 40 practice trials and 200 test trials. There were a total of eight indicator/symbol pairings (i.e., large circle/symbol 1, large circle/symbol 2, large circle/symbol 3, large circle/symbol 4, small circle/symbol 1, small circle/symbol 2, small circle/symbol 3, small circle/symbol 4), thus, creating 4 consistent pairs (i.e., a matching large and small shape, $\mathrm{xx}$ or ++ ) and 4 inconsistent pairs (i.e., mismatching large and small shape, $\mathrm{x}^{+}$or $+\mathrm{x}$ ). Each pairing was presented an equal number of times.

\section{Face Recognition}

Pilot Test Color mug shot photos of 110 White and 121 Black males were selected from the Florida Department of Corrections website for use in the study. All photographs were head- 
and-shoulder mug shots taken on a blue background with neutral expressions wearing standard blue jumpsuit attire. Faces with distinctive features (i.e., tattoos, facial hair, and glasses) were not included.

Using E-Prime software photographs were pre-tested by independent raters to determine average attractiveness and the degree to which each face possessed stereotypical Black features. Judgment procedures and instructions were modeled after Eberhardt and colleagues (2004, 2006). Twenty-four individuals rated the attractiveness of each Black face, while 25 different raters determined attractiveness of each White face after receiving the following instructions:

Your task is to rate the presented faces on their attractiveness on a scale between 1 and 7, with 1 being not at all attractive and 7 being extremely attractive. Your ratings should be based on your own opinions and criteria for attractiveness.

Furthermore, 31 individuals rated each Black face on stereotypicality. Instructions for the pretesting task read as such:

Your task is to rate each face on the degree to which it has features that are stereotypical of Black men. Your ratings will be on a scale of 1 and 7, with 1 meaning not at all and 7 meaning very much so. Your ratings should be based on your own opinions and criteria of what is stereotypical of Black men.

Present Study The final set of faces included 50 Black and 50 White mug shots. All faces were considered to be of average levels of attractiveness (Black photos: 1.67-2.38; White photos: 1.93-2.54). The Black faces were of varying degrees of stereotypicality including: 20 faces rated low in stereotypicality (i.e., non-stereotypical; $M=3.64$ ), 20 faces rated high in stereotypicality (i.e., stereotypical; $M=5.41$ ), and 10 faces considered to be average in stereotypicality ( $M=$ 4.58). A Pearson correlation confirmed that attractiveness and stereotypicality ratings were not 
related $r(50)=-.15, p>.05$. The photo set was split into two photo presentation groups (50 each; 25 Black: 10 non-stereotypical, 10 stereotypical, 5 average, 25 White) called old and new. Old faces were shown at encoding and new faces were shown in addition to the old faces during the recognition test for a total of 100 test photos.

Following Kleider, Cavrak, Knuycky, and Myers (2010) protocol, for the encoding phase each 3x5 mug shot was presented for 1 second followed by a 500ms black mask. For the recognition phase, each mug shot was again presented for 1 second followed by an unlimited response screen wherein participants were prompted to indicate whether the previously presented face was “old” or "new” by pressing the designated key. Immediately after a response was logged the next mug shot was presented.

\section{Individual Prejudice Survey}

The Bogardus (1925) Social Distance Scale (SDS), an established self-report measure of prejudice attitudes towards African Americans, was used to asses individual prejudice levels. Using E-Prime software participants were presented with the phrase 'I would be willing to have a White American person as my:' followed by a sequence of 15 nouns (e.g., next door neighbor, romantic date, governor, wife or husband). Participants rated the degree to which they agreed with each statement using a 9 point Likert-type scale. Next, participants were presented with the phrase 'I would be willing to have a Black American person as my:' followed by the same sequence of 15 nouns. Statement presentation and response time was unlimited. 


\section{Procedure}

Participants signed consent forms and were seated at one of eight individual computer stations. Participants were informed that the present study consisted of several tasks and that the specific directions for each task would be read as the session progressed.

Processing Focus-Type Task

Participants were told that for the first task we were interested in their ability to recognize symbols quickly and accurately. Their job was to use the indicator (i.e., large or small circle) to determine which or the two shapes (i.e., large or small shape) on the subsequent symbol screen to identify. Identifications were made via keyboard press of the appropriately labeled key.

\section{Face Recognition Task}

Encoding phase. Participants were informed that they would be taking part in a memory experiment wherein they would be presented a series faces that they would later be asked to recognize. Participants watched the encoding phase of the slideshow consisting of 50 faces each shown for 1 second.

Distracter phase. Following the slideshow participants were given a packet of word searches and told to locate as many words as possible in 15 minutes. After 15 minutes the experimenter instructed the participants to: stop searching, tally the total number of words found, and write the total on the top of the first word search.

Recognition phase. Participants were told to attempt to identify the faces from the earlier slideshow. For the recognition phase 100 faces were presented; half were "old" or previously presented and half were "new" or not previously presented. The face-type was distributed evenly 
between study and test phases. Presentation time was limited to 1 second per face but response time was indefinite.

\section{Individual Prejudice Survey Task}

Finally, the Bogardus (1925) Social Distance Scale (SDS) was administered. Participants were told that they would be answering questions regarding their opinions on various social issues. The true purpose of the measure was concealed until debrief in an effort to avoid biasing participant responses though the influence of demand characteristics or social desirability concerns. The session concluded with a brief demographic survey.

Following all tasks, participants were debriefed, thanked, and dismissed.

\section{Results}

Processing Focus-Type: Global versus Local

An individual's processing focus-type was determined by calculating the average reaction time to the inconsistent symbols (i.e., large $\mathrm{X}$ comprised of small $+\mathrm{s}$ and large + comprised of small xs) that were accurately identified separately for each indicator-type (i.e., large circle indicator $=$ global or small circle-indicator $=$ local $)$. Participants were considered global processors if they categorized inconsistent symbols faster when the large circle-indicator was presented than when the small circle-indicator was presented. If the converse was the case, and participants categorized inconsistent symbols faster when the small circle-indicator was presented than when the large circle-indicator was presented, then they were considered local processors. These calculations were made using only test trials.

Overall, participants accurately classified the symbols $90 \%$ of the time with an average reaction time of 680.51 milliseconds. Participants were faster (655.08 ms) and more accurate 
(96\%) when classifying the consistent than inconsistent symbols (705.94 ms, 84\%). Regarding the inconsistent trials of interest, when the circle-indicator was small local processors correctly categorized the symbol more quickly (679.11 ms) than global processors (723.35 ms).

Conversely, when the circle-indicator was large global processors correctly categorized the symbol more quickly (674.56 ms) than local processors (744.31 ms).

\section{Individual Prejudice: High versus Low}

Prejudice levels were calculated by summing participant responses to each of the 15 statements (i.e., 1-9) separately for each of the two question-types (White American person, Black American person). The response total of the questions pertaining to Black American persons was subtracted from the response total of the questions pertaining to White American persons. This calculation was performed separately for each participant. The resulting new prejudice scores were rank ordered from lowest (indicating a bias in favor of Black persons and reflecting low levels of prejudice) to highest (indicating a bias against Black persons and reflecting high levels of prejudice). A median split was conducted on the ordered list. In the present sample, the first 11 participants were labeled low in prejudice and the last 11 participants were labeled high in prejudice.

\section{Explanation of d' and C}

All hit (correctly identifying an old face as “old”) and false alarm (incorrectly identifying a new face as "old”) data were analyzed with signal detection procedures to ascertain accuracy $d$ ' scores and bias $C$ scores (Macmillan \& Creelman, 2005). Higher $d$ ' scores indicate better identification accuracy than lower scores. $C$ scores represent the criterion, or response bias, used to identify a face. The criterion scores range from conservative/strict (1.0), suggesting a tendency 
to not identify faces as “old,” to liberal/lax (-1.0), suggesting a tendency to identify faces as “old.”

\section{Hypotheses and Analyses}

Preliminary Analyses I first compared response rates to Black versus White faces collapsed across face-type and individual differences. A separate ANOVA was run for each of the four outcome variables (hits, false alarms, d’, C). Hit rates were equal for Black (61\%) and White $(62 \%)$ faces $[F(1,21)=.006] p=$ ns. False alarm rates were similar for Black $(32 \%)$ and White $(36 \%)$ faces $[F(1,21)=1.44] p=$ ns. There was no effect of face race on accuracy $[F(1,21)$ $=.94] p=$ ns (Black- .82, White- .71). Finally, participants were equally liberal/conservative when recognizing Black $(.11)$ and White $(.03)$ faces $[F(1,21)=.79] p=$ ns. It is surprising face race did not produce any reliable main effects supporting the CRE, however, it is likely that diversions in response rates due to Black face-type preclude a main effect of face race. That is, analyses collapsing across face-type may result in null findings for face race if response rates differ for stereotypical versus non-stereotypical Black faces.

Primary Analyses For the present experiment I hypothesized that face-type would influence White participants' cross-race face recognition such that non-stereotypical Black faces would be more accurately recognized than stereotypical Black faces and that participants would adopt a more liberal criterion for stereotypical compared to non-stereotypical Black face recognition. Furthermore, I was interested in how this relationship would be affected by individuals’ processing focus-type (global versus local) and prejudice (low versus high). White face recognition rates were not expected to be influenced by either factor.

To test these predictions I ran two sets of analyses, one for each face race set. For the Black faces I ran a 2 (face-type: stereotypical Black, non-stereotypical Black) x 2 (processing 
focus-type: global, local) x 2 (prejudice level: low, high) mixed-model ANOVA with processing focus-type and prejudice level as between-subjects factors. A separate ANOVA was run for each of the four outcome variables of interest (hits, false alarms, d’, C). As face-type (i.e., stereotypicality) was not varied for the White faces, a 2 processing focus-type (global, local) x 2 prejudice level (low, high) ANOVA was run for each of the four outcome variables of interest.

Hits Within the Black faces there was a main effect of face-type $\left[F(1,18)=6.79, M S_{e}=\right.$ $\left..03, \eta_{p}{ }^{2}=.27\right] p=.02$, wherein more hits were made to stereotypical Black faces (66\%) than to non-stereotypical Black faces (54\%). Processing focus-type also produced a reliable main effect $\left[F(1,18)=4.64, M S_{e}=.03, \eta_{p}^{2}=.21\right] p=.05$, due to the higher hit rate of local processors $(66 \%)$ than global processors (54\%). There were no other significant main effects or interactions.

The White faces did not produce any significant main effects or interactions.

False Alarms Within the Black faces there was a main effect of face-type $[F(1,18)=6.30$, $\left.M S_{e}=.01, \eta_{p}{ }^{2}=.26\right] p=.02$, wherein more false alarms were made to stereotypical faces (35\%) than to non-stereotypical faces (28\%). Processing focus-type again produced a reliable main effect $\left[F(1,18)=4.64, M S_{e}=.03, \eta_{p}{ }^{2}=.21\right] p=.05$, with local processors false alarming at a higher rate (37\%) than global processors (26\%). The processing focus-type by prejudice interaction produced a strong trend $\left[F(1,18)=4.20, M S_{e}=.03, \eta_{p}{ }^{2}=.19\right] p=.06$, with high prejudice global participants false alarming more (32\%) than low prejudice global participants (21\%) and low prejudice local participants false alarming more (41\%) than high prejudice local participants $(33 \%)$. Finally, the 3-way interaction was trending towards significance $[F(1,18)=$ 3.76, $\left.M S_{e}=.11, \eta_{p}{ }^{2}=.17\right] p=.07$. This interaction was primarily driven by the stereotypical faces wherein global processors high in prejudice false alarmed more (40\%) than global processors low in prejudice (20\%). Local processors had a higher false alarm rate to this face- 
type with those low in prejudice false alarming slightly more (46\%) than those high in prejudice (35\%). Overall, the false alarm rate was lower for the non-stereotypical faces, regardless of prejudice, and particularly so for global processors (global processors: low prejudice- 22\%, high prejudice- 24\%; local processors: low prejudice- 36\%, high prejudice- 30\%).

The White faces did not produce any significant main effects or interactions.

D' (Accuracy) There were no significant main effects or interactions produced by the accuracy variable for either the Black or White faces.

$C$ (Criterion Within the Black faces there was a main effect of face-type $[F(1,18)=$ 12.27, $\left.M S_{e}=.10, \eta_{p}{ }^{2}=.41\right] p<.01$, wherein participants were more liberal when recognizing stereotypical faces (-.03) than non-stereotypical faces (.29). Processing focus-type produced a reliable main effect $\left[F(1,18)=8.79, M S_{e}=.18, \eta_{p}{ }^{2}=.33\right] p<.01$, with local processors setting a more liberal criterion (-.06) than global processors (.32). Finally, the 3-way interaction was trending toward significance $\left[F(1,18)=3.45, M S_{e}=.10, \eta_{p}{ }^{2}=.16\right] p=.08$ (see Figure 2) and followed the false alarm rate pattern. This interaction was the result of processing focus-type and prejudice level affecting recognition criterion for stereotypical but not non-stereotypical faces. Specifically, when recognizing stereotypical Black faces global processors high in prejudice were more lax (.02) than global processors low in prejudice (.46). Local processors instead set a less strict criterion overall, especially when they were low in prejudice (low prejudice- -.43, high prejudice- -.07). In contrast, non-stereotypical faces elicited a more conservative criterion shift overall, regardless of prejudice, and particularly so for global processors (global processors: low prejudice- .33, high prejudice- .46; local processors: low prejudice- .14, high prejudice- .12 ).

The White faces did not produce any significant main effects or interactions. 


\section{Discussion}

Results partially supported the hypothesis. Findings revealed, contrary to expectation, that face-type (i.e., stereotypical versus non-stereotypical) did not affect White participant's cross-race face recognition accuracy. However, as predicted, it did impact criterion scores. Generally, stereotypical (versus non-stereotypical) Black faces elicited a more liberal recognition pattern such that White participants recognized a stereotypical Black face as 'old' more often than non-stereotypical Black faces which were more often called 'new.' Furthermore, individual differences in processing focus-type and prejudice differentially affected participant's recognition of stereotypical and non-stereotypical Black faces. Specifically, global processors low in prejudice were equally liberal/conservative when recognizing any Black face, however, global processors high in prejudice were much more liberal when recognizing stereotypical than non-stereotypical Black faces. This is consistent with a holistic (i.e., global) face processing style which is more protective against false alarms than a detail oriented (i.e., local) processing style (Michel, et al., 2006). However, high individual prejudice appears to counter the advantages afforded by a global processing style when recognizing stereotypically Black faces. In other words, when recognizing stereotypical Black faces, a global processing style facilitated a conservative recognition criterion compared to a local processing style except when coupled with a high level of prejudice. This tendency is consistent with social identity theory which predicts that persons strongly identified with an in-group will take more care in maintaining a boundary between their own and other groups (see Blascovich, Wyer, Swart, \& Kibler, 1997). Thus, high prejudice individuals seemingly distinguish between non-stereotypical and stereotypical Black face-types categorizing the latter as simply 'Black' (i.e., out-group). Grouping the stereotypical Black faces into a 'Black’ category promotes global processors to misjudge stereotypical Black 
faces as familiar, the most common error in cross-race face recognition (Meissner \& Brigham, 2001). This finding suggests that non-stereotypical Black faces may be judged as in-group members and individuated similar to other same-race faces. Stereotypical Black faces are therefore judged ‘Black’ and processed like out-group faces.

Local processors were more liberal when recognizing cross-race faces generally suggesting that looking at the details, as opposed to the big picture, causes all Black face-types to look familiar. Furthermore, local processors low in prejudice were more liberal when recognizing stereotypical than non-stereotypical faces. The directionality of the criterion bias was the same for local processors high in prejudice but this difference was not significant. The current results suggest that local processors are more liberal when recognizing stereotypical than non-stereotypical faces and particularly so when their prejudice level is low.

It has been suggested that the liberal criterion shift observed for the stereotypical Black faces was the result of this face-type appearing more alike than the non-stereotypical Black faces. Stated differently, the stereotypical Black faces potentially vary less in appearance than the non-stereotypical Black faces causing the former face-type to elicit more 'old' responses because they appear similar to previously seen faces. However, if this were the case accuracy scores (i.e., d') should have been higher for participants when recognizing the non-stereotypical versus stereotypical Black faces. There was no difference in recognition accuracy as a function of face-type; thus, discrimination among stereotypical and non-stereotypical faces was equal.

While the present study has interesting implications for cross-race face recognition generally it is lacking any realistic context. Thus, for my second experiment face recognition is tested in a lineup paradigm with participants acting as eyewitnesses to a crime. 
CHAPTER THREE.

\section{EXPERIMENT 2}

\section{Overview and Analyses}

Experiment 1 found that face-type had no effect on recognition accuracy; however, facetype did impact bias. Thus, the primary motivation for the second study was to learn how such bias (i.e., criterion shift to misrecognize stereotypical Black faces as familiar) impacts cross-race face identification in an applied context. To that end, participants witnessed one of two Black actors (stereotypical, non-stereotypical) commit a mock crime and then, after a delay, attempted to identify the 'perpetrator’ from a lineup. If stereotypical Black facial features are associated with criminality then participants should identify lineup faces that engender greater stereotypical ratings than the actual witnessed 'perpetrator.' While I anticipate that both actors will activate the criminal stereotype to some degree, the non-stereotypical actor may violate expectations of the 'typical criminal’ and lead to fewer lineup identifications. Individual differences in processing focus-type and prejudice were collected and, following Experiment 1, are expected to predict choosing behavior (i.e., choosing a lineup face or 'not present').

In Experiment 2, participants completed a total of three tasks in the following order: processing focus-type task, face identification, and individual prejudice survey. The face identification task, like the face recognition task in Experiment 1, was comprised of three phases; during the encoding phase participants witnessed a crime via a recorded video depicting a Black and White assailant commit grand-theft auto. After a fifteen minute distracter phase, participants completed the test phase where they identified the two perpetrators from a lineup. The lineup task used a 2 lineup type (target-present, target-absent) x 2 perpetrator (stereotypical perpetrator, 
non-stereotypical perpetrator) between-subjects design with the stereotypicality rating of the identified mug shot as the outcome variable.

\section{Participants}

A total of 105 White (77 female) undergraduate students were recruited from introductory psychology courses at Georgia State University in exchange for course credit. Participants were randomly assigned to each of the study conditions (stereotypical target-present16, stereotypical target-absent- 33, non-stereotypical target-present- 25, non-stereotypical targetabsent- 31) and were run in groups of 2 to 8 during experimental sessions.

\section{Materials}

\section{Face Identification Task}

Encoding phase. The 3 minute video clip depicts a Black man (either stereotypical or non-stereotypical) with a White accomplice committing grand-theft-auto, a Black race-congruent crime (Jones, et al., 2003). The film, shot by a ‘tourist,' opens with “regular” leisure activity in a busy park near a downtown city. The two perpetrators are shown casing cars in the area. After focusing in on the conspicuous looking perpetrators, the two men approach a woman unpacking a stroller from her car parked on a side street. The Black man is armed with his gun visible. The film has a "homemade quality" in an attempt to mimic what an actual bystander may witness. The Black man is shown as the primary aggressor, grabbing the woman, pointing the gun toward her, and taking the keys to her car while demanding that she get down on the ground facing away from the perpetrators. The White man acts as a watchman. The woman looks distressed but does 
as the assailants instruct and is released. The scene closes with the two men jumping into the car and speeding off.

Identification phase. A target-present and target-absent lineup comprised of 5 photos each was constructed for the stereotypical Black, non-stereotypical Black and White perpetrators. The faces used in the lineups were pre-rated in pilot studies. Ratings of attractiveness and stereotypicality (based on a 7 point Likert-type scale) were collected for 50 Black faces (including the stereotypical and non-stereotypical Black perpetrators) while only attractiveness ratings were collected for 50 White faces (including the White perpetrator).

The lineups for the Black perpetrators were constructed by first taking the average stereotypicality rating for the 50 Black faces $(M=4.5, \mathrm{SD}=.8)$. Next, the standard deviation was added/subtracted to the rating ascribed to the target perpetrator face (stereotypical: 5.14; nonstereotypical: 3.71) in order to calculate the stereotypicality rating of the most (+2) and least (-2) stereotypical foils in the lineup. One half of the standard deviation (i.e., .4) was added/subtracted to the target rating assigned to the target face to calculate the rating of the more $(+1)$ and less $(-1)$ stereotypical foils in the lineup. Finally, the target perpetrator face completed the target-present lineup while a foil with an equivalent (attractiveness and stereotypicality) rating was used to replace the perpetrator in the target-absent lineups. All faces were similar (i.e., average) in attractiveness. The White lineup was constructed by using the pilot ratings to identify foils that were considered to be of average attractiveness. Again, the target perpetrator face completed the target-present lineup while a foil with an equivalent attractiveness rating was used to replace the perpetrator in the target-absent lineups. A "Perpetrator Not Present" and "Not Sure" option was available in all lineup types. The presentation order for the lineup was always Black then White 
as the Black identification is the outcome variable of interest and it is unknown what effect (if any) an intervening lineup for a different race perpetrator may have on later identifications.

\section{Procedure}

Participants signed consent forms and were seated at one of eight individual computer stations. Participants were informed that the study consisted of several tasks and that the specific directions for each task would be read as the session progressed.

Processing Focus-Type Task

The processing focus-type task followed the same protocol as Experiment 1. Face Identification Task

Encoding phase. Participants were only told that they would be watching a short video clip and to pay close attention because it would be relevant later in the study. No additional instructions were given in an effort to partially simulate the surprise surrounding an eyewitness situation

Distracter phase. Identical to procedures in Experiment 1 participants were given 15 minutes to work on several word search puzzles.

Identification phase. Participants were reminded of the video wherein a Black assailant and a White assailant assaulted a victim and stole her car. They were then asked to make lineup identifications of the two perpetrators from the crime in two separate lineups (1 Black, 1 White). They were informed that the actual perpetrator may or may not be present. Perpetrator choice was registered by pressing the computer key corresponding to lineup position. Half of the participants were presented a lineup with the target perpetrator present whereas the other participants were presented a lineup without the target perpetrator present. The choice made on 
the target-absent lineup is of primary interest as it most closely approximates the situations that lead to a false identification, as witnesses feel compelled to select "someone" -----even though the police do not know whether they have the actual perpetrator in their lineup (Wells, Memon, \& Penrod, 2006). The purpose of the target-present lineup was to ensure that choices made in the target-absent lineup were not random, that is, to show that participants generally have memory for the actual perpetrator when he is presented. Following each lineup choice, participants were asked to rate their confidence in their decision on a 1-7 Likert-type scale reflecting 'not at all sure' and 'complete confidence' at the extreme ends.

Individual Prejudice Survey Task

Following the procedures used in Experiment 1, the Bogardus (1925) social distance scale was again administered in an effort to assess individual prejudice levels.

Upon completion of all tasks participants were debriefed and dismissed.

\section{Results}

\section{Processing Focus-Type: Global versus Local}

As in Experiment 1, an individual's processing focus-type was again calculated using the average reaction time to inconsistent symbols that were accurately identified separately for each cue-type (i.e., global or local). Participants were labeled as global processors if they categorized inconsistent symbols faster when the large circle-indicator than when the small circle-indicator was presented and local processors if they categorized inconsistent symbols faster when the small circle-indicator than when the large circle-indicator was presented.

Overall, participants accurately classified the symbols $88 \%$ of the time with an average reaction time of 738.54 milliseconds. Participants were faster $(710.60 \mathrm{~ms})$ and more accurate 
(93\%) when classifying the consistent than inconsistent symbols (766.62 ms, 83\%). Regarding the inconsistent trials of interest, when the circle-indicator was small local processors correctly categorized the symbol more quickly (636.12 ms) than global processors (853.86 ms).

Conversely, when the circle-indicator was large global processors correctly categorized the symbol more quickly (724.08 ms) than local processors (792.71 ms).

\section{Individual Prejudice: High versus Low}

Prejudice levels were calculated using the same procedures used in Experiment 1. The prejudice scores were rank ordered from lowest to highest and split separately for each of the four lineup conditions (stereotypical target-present, stereotypical target-absent, non-stereotypical target-present, non-stereotypical target-absent).

\section{Hypotheses and Analyses}

Manipulation Check In order to ensure that participants attended to the event, I conducted a chi-square analysis comparing accurate versus inaccurate lineup selections in both target present and absent lineups (Note: this calculation excluded 'not sure’ selections). Consistent with previous research (Wells, et al., 2006), lineup selections were more accurate in target present $(73 \%)$ than target absent $(28 \%)$ lineups $X^{2}(1, N=63)=3.10, p=.08$.

Prediction 1- Choosing Behavior: First, choosing behavior was examined without considering decision accuracy. This analysis was important as it included participants choosing the 'not sure' option. A 'not sure' choice could not be classified as either accurate or inaccurate; however, it was a relatively more conservative decision than a positive lineup selection (i.e., selecting any face from the lineup). Experiment 1 suggests that certain individuals make more liberal versus conservative decisions and that specific face-types elicit a more liberal recognition criterion than others. Thus, experiment 1 criterion results are most comparable to experiment 2 
overall choosing behaviors. Consistent with the findings from Experiment 1 the stereotypical actor should engender more positive lineup selections as a function of processing focus-type. Specifically, local processors should make more positive lineup selections than their global processor counterparts. In addition, high compared to low prejudice individuals that are also local processors, should make more positive lineup selections. There were no expectations for individual differences, either processing focus-type or prejudice level, affecting positive lineup identifications for the non-stereotypical actor.

A separate logistic regression was run for each of the two actor types to test prediction one. Processing focus-type (global, local) and individual prejudice (low, high) were used as predictors, and choosing (the decision to make a positive face identification) versus not choosing (not making a positive identification by selecting 'not sure' or 'not present') was the outcome variable. This prediction was supported. Analyses revealed a significant two-way interaction of processing focus-type and prejudice on positive identifications made after witnessing the stereotypical 'perpetrator' ( $p=.02$; see Figure 3 ). Specifically, local processors high in prejudice were more likely to make a positive identification (80\%) than local processors low in prejudice (25\%). Global processors lineup identifications were unaffected by prejudice level (high- 26\%, low-53\%). Conversely, after witnessing the non-stereotypical 'perpetrator,' global and local processors of high and low prejudice were equally likely to make an identification (local: high57\%, low- 50\%; global: high- 39\%, low- 63\%).

Prediction 2- Accuracy of Lineup Decisions: If individual differences in processing style and prejudice influence choosing behavior, then these factors should similarly influence whether a witness will identify a perpetrator from a lineup (if he is present) or reject all foils (if he is not present). Thus, as found with holistic processing (Michel, et al., 2006), global versus local 
processors should demonstrate superior face identification accuracy. Prejudice level alone was not expected to influence lineup identification accuracy. Local processors high in prejudice should make more identification errors than local processors low in prejudice. Prejudice level should not affect global processors identification decisions.

A logistic regression was used to test prediction 2. Processing focus-type (global, local) and individual prejudice (low, high) were used as predictors and decision accuracy (accurate, inaccurate) was the primary outcome variable of interest. Participants indicating that they were 'not sure' enough to make a lineup decision were excluded from the analysis as they could not be classified as having made either an accurate or inaccurate decision. Results produced a reliable main effect of processing focus-type, as well as a significant two-way interaction ( $p=.01$; see Figure 4). Local processors high in prejudice made less accurate lineup decisions (13\%) than local processors low in prejudice (67\%). Global processors made equally accurate lineup identifications regardless of individual prejudice (high prejudice- 35\%, low prejudice- 17\%).

The number of participants making accurate lineup decisions as a function of individual differences and face-type was highly variable. As a result of the lack of power in these experimental cells statistical analyses were not viable. For the purposes of comparison see Table 1 for descriptive statistics.

Prediction 3- Stereotypicality of Lineup Identifications: If Black faces with stereotypical features better fit the criminal stereotype (Dixon \& Maddox, 2005; Eberhardt, et al., 2004; Eberhardt, et al., 2006; Kleider, et al., 2010) and elicit misplaced feelings of recognition more often than foils rated as less stereotypical (see Experiment 1) then lineup foils considered to be more stereotypical than the witnessed 'perpetrator' should be chosen by participants during the lineup task. Specifically, I predicted that after witnessing either actor (stereotypical, non- 
stereotypical) commit the crime participants would identify a more stereotypical (over a less stereotypical) face when making a decision in both target present and target absent lineup-types. If the average stereotypicality rating of the face chosen from the lineup is significantly greater than zero then these predictions are supported.

A single sample t-test was conducted separately for each of the four lineup-types (stereotypical actor/target present, stereotypical actor/target absent, non-stereotypical actor/target present, non-stereotypical actor/target absent) with the stereotypicality score $(-2,-1,0,1,2)$ as the dependant variable. Results partially supported predictions (see Figure 5). Specifically, the stereotypicality score of identifications made in the stereotypical/target present lineup were significantly greater than zero $\mathrm{t}(5)=2.71, p=.04(M=.833)$. However, the score of identifications made in the stereotypical/target absent lineup were not different from zero $\mathrm{t}(13)=-.68, p=\mathrm{ns}(M=$ -.21). In regard to the stereotypicality score of identifications made for the non-stereotypical actor, when the actor was present in the lineup, scores were not different from zero $\mathrm{t}(14)=.25, p$ $=\mathrm{ns}(M=.067)$. Contrary to expectation, when the actor was absent from the lineup scores were significantly less than zero $\mathrm{t}(14)=-2.43, p=.04(M=-.933)$.

Prediction 4- Confidence in Lineup Decisions: Finally, I was interested in the degree of confidence participants expressed in their lineup decisions. I evaluated the level of confidence reported for positive-identifiers (i.e., persons selecting any face from the lineup) versus negativeidentifiers (i.e., persons selecting 'not present' when presented with the lineup array) that were both accurate and inaccurate in their decisions. Since confidence ratings were taken immediately after lineup decisions they should be reflective of accuracy (i.e., calibrated) for positiveidentifiers but not for negative-identifiers (Sporer, 1992). Stated differently, (prediction 4a) positive-identifiers making accurate lineup decisions should report greater confidence in their 
choice than positive-identifiers making inaccurate lineup decisions. Confidence scores for negative-identifiers should be equivalent regardless of accuracy.

A separate univariate ANOVA was performed for positive-identifiers and negative identifiers with accuracy as the between-subjects variable and confidence rating as the outcome variable of interest. As expected (see Figure 6), there was a significant effect of accuracy for positive-identifiers $\left[F(1,49)=4.35, M S_{e}=1.71 ; \eta_{p}{ }^{2}=.08\right] p=.04$, as participants making accurate lineup identifications reported greater confidence in their identification $(M=4.55)$ than participants making inaccurate lineup identifications ( $M=3.62)$. Conversely, negative-identifiers were equally confident in their 'not present' decision regardless of accuracy (accurate- 4.25, inaccurate- 5.00) $[F(1,12)=0.75, p=\mathrm{ns}]$.

Further, I was interested in the effect of accuracy on confidence for positive-identifiers as a function of perpetrator face-type. As each lineup was prepared using the stereotypicality rating of the perpetrator, the lineup presented for participants witnessing the stereotypical actor necessarily includes more stereotypical faces. Thus, it is likely that the faces in this lineup elicited greater feelings of familiarity. Therefore, I anticipated that (prediction 4b) participants making a positive-identification using this lineup-type would have a less calibrated sense of confidence in their face identification than participants making lineup decisions after witnessing the non-stereotypical perpetrator.

To test this prediction a separate univariate ANOVA was performed for positiveidentifiers in the stereotypical and non-stereotypical actor conditions. Findings revealed that when participants witnessed the non-stereotypical actor commit the crime there was a reliable effect of accuracy $\left[F(1,29)=5.63, M S_{e}=1.80 ; \eta_{p}{ }^{2}=.17\right] p=.03$, wherein participants making accurate identifications were more confident $(M=4.56)$ than participants making inaccurate 
identifications $(M=3.29)$. However, as predicted participants that witnessed the stereotypical actor commit the crime reported equal levels of confidence in their lineup identifications regardless of accuracy (accurate- 4.5, inaccurate- 4.0). See Figure 7 for a pictorial depiction of this result.

\section{Discussion}

Results supported the broad hypothesis (predictions one and two) that the actor's face-type would impact cross-race face identification via choosing behavior and accuracy. Individual differences in processing focus-type and prejudice are put forth as the mechanisms underlying the biases. Generally, a local processing style coupled with high individual prejudice resulted in an increased tendency to make a face identification when the witnessed 'perpetrator' was stereotypical. However, these same individuals were also the least accurate when making any lineup decisions.

In partial support of prediction three, when the stereotypical actor was present in the lineup participants identified significantly more stereotypical foils than the actor himself. When the stereotypical actor was absent from the array the stereotypicality of the foils identified were equivalent to that of the witnessed 'perpetrator.' Contrary to hypotheses, the non-stereotypical actor did not elicit mistaken identifications erring in the stereotypical direction. Instead, the stereotypicality scores of the identifications made when the non-stereotypical 'perpetrator' was present in the lineup did not differ from zero suggesting that the primary identification was the actual actor. When the non-stereotypical actor was absent from the lineup array identifications erred in the less stereotypical direction. That is, on average, participants identified a lineup face less stereotypical than the witnessed actor when he was non-stereotypical. It is possible that the 
stereotypical, compared to the non-stereotypical, actor better fit the criminal stereotype. If the non-stereotypical actor was discordant with the viewer's expectations his appearance may have become a memorable aspect of the crime scene. Thus, participants likely remembered that the 'perpetrator' was unexpectedly non-stereotypical and used this information when making lineup decisions.

Finally, as expected confidence ratings were accurately calibrated for positive, but not negative, identifications. In further decomposing this result, findings revealed that participants reported greater confidence in accurate (than inaccurate) positive identifications when presented with the lineup array for the non-stereotypical actor. However, when presented with the lineup array for the stereotypical actor, participants reported equal levels of confidence in their accurate and inaccurate decisions.

Overall, face identification accuracy rates were low. The factors enhancing the difficulty of the task in the present study are all common to real lineup situations. Specifically, experts know that identifications made after encountering a cross-race stranger with a weapon for short exposure duration are notoriously inaccurate. However, the present study provides information further informing the most common error in cross-race face recognition, mistakenly recognizing a new (unseen) face as previously seen. Particularly, results reveal that stereotypical, compared to non-stereotypical, Black faces more commonly engender misplaced feelings of familiarity making them the most likely target of false-positive identifications. 


\section{CHAPTER FOUR. \\ GENERAL DISCUSSION}

The overall aim of the present investigation was to test whether facial features associated with ethnic group membership influenced cross-race face recognition and whether any realized effects would impact eyewitness identification in subsequent lineup selections. Moreover, results from this series of studies may indicate possible cognitive mechanisms that underlie cross-race misidentifications which ultimately promote faulty convictions.

Findings revealed that the indexed stereotypicality of Black facial features influenced cross-race face recognition (Experiment 1) and lineup identification (Experiment 2). In Experiment 1, I predicted that Black faces possessing stereotypical versus non-stereotypical facial features would be less accurately recognized. In addition, these faces were expected to elicit greater feelings of familiarity resulting in persons setting more liberal judgment criterions such that 'new' faces were more often called 'old.' This hypothesis was partially supported as participants were more likely to judge stereotypical faces as 'old' than non-stereotypical faces; however, face recognition accuracy was not influenced by face-type. Individual differences in processing focus-type and prejudice level predicted the liberal criterion shift that occurred when recognizing stereotypical Black faces. Specifically, local processors set a more liberal criterion than global processors when recognizing these faces. Previous research has linked a holistic processing strategy (i.e., global) with superior same-race face recognition (Michel, et al., 2006) wherein a stringent recognition criterion is common (Sporer, 2001). Thus, it follows that a local processing strategy resulted in a relatively lax recognition criterion. While global processors’ recognition criterion was generally conservative it was especially so when coupled with a low (versus high) level of prejudice. It was surprising that local processors low in prejudice adopted a 
more liberal criterion; however, it should be noted that this unexpected pattern was not replicated in Experiment 2. These disparate findings are worthy of further investigation in the future.

In Experiment 2, a similar shift in bias was realized in a more realistic context. Specifically, in support of hypothesis one, participants were more likely to make a positive lineup identification (i.e., select any face from the lineup) after witnessing the stereotypical than non-stereotypical actor commit a stereotypically Black crime. Individual differences in processing focus-type and prejudice level predicted choosing (i.e., making any definitive lineup decision) behavior. Specifically, individual level of prejudice did not affect global processors’ decision to make a face identification. Local processors high in prejudice set the most lax criterion, making a face identification $80 \%$ of the time. Contrary to the results from Experiment 1, but consistent with expectations, local processors low in prejudice were relatively conservative, making a face identification only $26 \%$ of the time.

Hypothesis one is best interpreted in concert with hypothesis two wherein I predicted that participants with a local processing style coupled with a high level of prejudice would make especially inaccurate lineup decisions. Hypothesis two was supported. While level of prejudice did not affect global processors identification accuracy, local processors low (versus high) in prejudice made significantly more accurate lineup decisions. Local processors high in prejudice made accurate lineup decisions only $13 \%$ of the time while those low in prejudice made accurate decisions $67 \%$ of the time. Because of a small sample size in some cells, statistical analysis could not be run to compare lineup decision accuracy for global versus local processors as a function of prejudice and actor-type. However, the descriptive statistics (see Table 1) show that the high degree of lineup accuracy achieved by local processors low in prejudice occurred exclusively for decisions rendered after witnessing the non-stereotypical actor commit the crime. Hypothesis one 
and two together suggest that local processors high in prejudice are the most likely participants to make a positive-lineup decision but the least likely to be accurate. In a criminal setting this would be an error such that an innocent suspect would be falsely identified as the perpetrator of a crime. This is the number one cause of wrongful convictions. Further, this finding suggests that the disadvantages in face recognition assumed with a local processing style can be overcome when coupled with a low level of prejudice. A low, versus high, level of prejudice likely leads to an increased motivation to further individuate a cross-race face. It is known that individuation information is particularly necessary for reliable out-group face recognition (Malpass, 1990).

For hypothesis three, I expected that participants would identify a foil more stereotypical than the actual 'perpetrator' regardless of the actor witnessed committing the crime. This prediction was partially supported. When the stereotypical actor was in the presented lineup array, participants misidentified a foil with an indexed stereotypicality rating greater than the 'perpetrator' witnessed committing the crime. When the stereotypical actor was absent from the lineup array, participants misidentified a foil with an indexed stereotypicality rating equal to the 'perpetrator' witnessed committing the crime.

Contrary to prediction, the non-stereotypical actor elicited lineup misidentifications when the actor was absent from the lineup array but in the opposite direction from that of the stereotypical actor. Specifically, participants inaccurately identified foils with an indexed stereotypicality rating less than the witnessed 'perpetrator.' One possible explanation for this finding is that people remembered that the actor violated expectations regarding the typical criminal (i.e., non-stereotypical) and thus, they used that factor during lineup selection leading participants to pick any non-stereotypical foil. I suggest that the time delay used between the presentation of the perpetrator and the memory test in the current study was insufficient to 
induce participant reliance on schemas. A longer delay may force the memorial event into 'gist' memory (Reyna \& Brainerd, 1995) and result in more stereotypical identification errors (see Kleider et al., 2008).

Finally, prediction four was supported as participants making positive lineup identifications reported greater confidence in their accurate than inaccurate decisions. There was not a significant confidence/accuracy relationship for participants making a negative lineup decision (i.e., choosing 'not present'). Of applied interest, among participants making a positive lineup identification, only those witnessing the non-stereotypical actor commit the crime recorded a calibrated confidence score. That is, participants witnessing the stereotypical actor commit the crime reported being equally confident in their positive lineup decisions regardless of accuracy.

\section{Theoretical Implications}

The bias shifts realized in the present study were driven by stereotypical, compared to the non-stereotypical, Black faces. This finding supports the conclusion that all Black faces are not processed equally as implied by the current CRE theories. Specifically, the perceptual-expertise theory suggests that the CRE is due to a lack of experience with cross-race faces resulting in a tendency to process them more feature-based and less holistically (Michel, et al., 2006). The current study partially supports this theory as a feature-based processing style (i.e., local) was relatively detrimental to cross-race face recognition but only for stereotypical and not nonstereotypical Black faces. In regard to the perceptual-expertise theory the present pattern of findings suggests that either, 1) non-stereotypical Black facial features are considered more similar to White faces compared to stereotypical Black faces and therefore are afforded the same 
processing advantages extended to own-race faces or, 2) the CRE is not due to expertise as a function of experience as it is unrealistic that participants more often encounter nonstereotypical, than stereotypical, Black faces.

Alternatively, the social-categorization theory posits that people are motivated to process faces from their in-group more deeply than faces from their out-group (Rodin, 1987). Again, results provide some support for this theory as stereotypical, but not non-stereotypical, Black faces were subject to the lax shift in criterion ubiquitous in the CRE. This bias was driven by local processors and was mediated by individual level of prejudice (see Experiment 2). Specifically, participants with a local processing style that were high, versus low, in prejudice were particularly likely to make a positive lineup decision. In regards to the social-categorization theory this result suggests against motivation being the only factor influencing cross-race face recognition as global, compared to local, processors were relatively conservative when recognizing cross-race faces regardless of prejudice level.

Overall, results suggest that attempting to understand the mechanisms underlying the CRE may be best achieved by considering these theories in concert; processing style and motivation each influenced cross-race face recognition. Furthermore CRE theories should reflect the fact that all Black faces are not processed equally, rather, the stereotypicality of facial features differentially affects cross-race face recognition.

\section{Practical Implications}

The liberal shift in face recognition/identification observed for stereotypical but not nonstereotypical faces in the present study is of particular significance because it is this bias that causes false-positive identifications. Recall that false-positive identifications (or 
misidentifications) are the number one cause of wrongful convictions. Thus, the current results suggest that Black men possessing stereotypical, compared to non-stereotypical, facial features are at an increased risk of being mistakenly identified as the perpetrator of a crime. Of further interest was the confidence ratings participants reported in their positive identifications. Specifically, participants witnessing the non-stereotypical actor commit the crime were more confident when they made accurate than inaccurate face identifications. However, participants witnessing the stereotypical actor commit the crime were equally confident in their accurate and inaccurate face identifications. Jurors often rely on witness confidence to infer accuracy. Thus, this lack of confidence/accuracy calibration could further exacerbate the negative consequences for a stereotypical Black man that has been misidentified as the perpetrator of a crime.

\section{Limitations and Future Directions}

The 15 minute time lapse between the presentation of the crime scene and lineup array in Experiment 2 is unrealistic of the actual delay an eyewitness would experience. A longer delay should result in greater memory fade (Reyna \& Brainerd, 1995) and more reliance on stereotypic information (Kleider, et al., 2008). Thus, the present investigation likely paints a conservative picture of the problems plaguing true lineup identifications. Previous researchers have shown that a sequential lineup forces persons to adopt an absolute judgment strategy which reduces false-positive identifications (Lindsay \& Wells, 1985). Therefore, future studies may investigate whether the liberal bias shift observed for stereotypical Black faces can be reduced or even eliminated by presenting eyewitnesses with a sequential, as opposed to a simultaneous, lineup. 


\section{Conclusion}

The findings from the present study further inform the cross-race effect and suggest that some misidentifications may be systematic. Specifically, Black faces possessing stereotypical, compared to non-stereotypical, facial features elicited greater feelings of misplaced familiarity and were more commonly the target of false-positive identifications. That is, stereotypical Black faces drove the lax criterion shift ubiquitous to the CRE. Moreover, individual differences in processing focus-type and prejudice level predicted these liberal shifts in bias. Together these factors are suggested as cognitive mechanisms contributing to the CRE. Findings provide strong support for the conclusion that cross-race face recognition is more than just a 'Black and White' issue. 


\section{REFERENCES}

Alba, J. W., \& Hasher, L. (1983). Is memory schematic? Psychological Bulletin, 93, 203-231.

Anthony, T., Copper, C., \& Mullen, B. (1992). Cross-racial facial identification: A social cognitive integration. Personality and Social Psychology Bulletin, 18, 296-301.

Blair, I. V., Judd, C. M., \& Chapleau, K. M. (2004a). The influence of Afrocentric facial features in criminal sentencing. Psychological Science, 15, 674-679.

Blair, I. V., Judd, C. M., \& Fallman, J. L. (2004b). The automaticity of race and Afrocentric facial features in social judgments. Journal of personality and Social Psychology, 87, 763-778.

Blair, I. V., Judd, C. M., Sadler, M. S., \& Jenkins, C. (2002). The role of Afrocentric features in person perception: Judging by features and categories. Journal of Personality and Social Psychology, 83, 5-25.

Blascovich, J., Wyer, N. A., Swart, L. A., Kibler, J. L. (1997). Racism and racial categorization. Journal of Personality and Social Psychology, 72, 1364-1372.

Bogardus, E. S. (1925). Measuring social distance. Journal of Applied Sociology, 9, 299-309.

Dixon, T. L. \& Maddox, K. B. (2005). Skin tone, crime news, and social reality judgments: Priming the stereotype pf the dark and dangerous black criminal. Journal of Applied Social Psychology, 35, 1555-1570.

Duncan, B. L. (1976).Differential social perception and attribution of intergroup violence: Testing the lower limits of stereotyping of Blacks. Journal of Personality and Social Psychology, 34, 590-598. 
Eberhardt, J. L., Davies, P. G., Purdie-Vaughns, V. J., \& Johnson, S. L. (2006). Looking deathworthy perceived stereotypcality of black defendants predicts capital-sentencing outcomes. Psychological Science, 17, 383-386.

Eberhardt, J. L., Goff, P. A., Purdie, V. J., Davies, P. G. (2004). Seeing black: Race, crime, and visual processing. Journal of Personality and Social Psychology, 87, 876-893.

Fiske, S. T. (2004). Social beings: A core motives approach to social psychology. Hoboken, NJ: Wiley.

Goldstein, E. B. (2005). Cognitive Psychology. Belmont, CA: Thomson/Wadsworth.

Haber, R. N., \& Haber, L. (2000). Experiencing, remembering and reporting events. Psychology, Public Policy, and Law, 6, 1057-1097.

Holst, V. F., \& Pezdek, K. (1992). Scripts for typical crimes and their effects on memory for eyewitness testimony. Applied Cognitive Psychology, 6, 573-587.

Huff, R., Ratner, A., \& Sagarian,E. (1986). Guilty until proven innocent. Crime and Delinquency, 32, 518-544.

Hugenberg, K., Miller, J., Claypool, H. M. (2007). Categorization and individuation in the crossrace recognition deficit: Toward a solution to an insidious problem. Journal of Experimental Social Psychology, 43, 334-340.

Innocence Project. Retrieved January 18, 2008 from the World Wide Web: http://www.innocenceproject.org/about/Mission-Statemant.php.

Jones, C. S. \& Kaplan, M. F. (2003). The effects of racially stereotypical crimes on juror decision-making and information-processing strategies. Basic \& Applied Psychology, 25, $1-13$. 
Kleider, H. M., Cavrak, S., Knuycky, L., \& Myers, A. (unpublished). Stereotypical errors in face recognition: Negative prime causes false recognition of stereotypically Black faces.

Kleider, H. M., Knuycky, L., Cavrak, S., \& Myers, A. (unpublished). Trouble with “loaded” juries: Cognitive load increases racial bias in mock-jury decisions. Applied Cognitive Psychology.

Kleider, H. M., Pezdek, K., Goldinger, S. D., \& Kirk, A. (2008). Schema-Driven source misattribution errors: Remembering the expected from a witnessed event. Applied Cognitive Psychology, 22, 1-20.

Lindsay, R. C. L., \& Wells, G. L. (1985). Improving eyewitness identifications from lineups: Simultaneous versus sequential lineup presentation. Journal of Applied Psychology, 70, 556-564.

Livinston, R. W., \& Brewer, M. B. (2002). What are we really priming? Cue-based versus category-based processing of facial stimuli. Journal of Personality and Social Psychology, 82, 5-18.

MacLin, M. K., \& Herrera, V. (2006). The criminal stereotype. North American Journal of Psychology, 8, 197-208.

Malpass, R. S. (1990). An excursion into utilitarian analysis. Behavior Science Research, 24, 115.

Meissner, C. A., \& Brigham, J. C. (2001). Thirty years of investigating the own-race bias in memory for faces: A meta-analytic review. Psychology, Public Policy, and Law, 7, 3- 35.

Meissner, C. A., Tredoux, C. G., Parker, J. F., \& MacLin, O. H. (2005). Eyewitness decisions in simultaneous and sequential lineups: A dual-process signal detection theory analysis. Memory \& Cognition, 33, 783-792. 
Michel, C., Rossion, B., Han, J., Chung, C. S., \& Caldara, R. (2006). Holistic processing is finely tuned for faces of one’s own race. Psychological Science, 17, 608-615.

Oliver, M. B. (1999). Caucasian viewer's memory of Black and White criminal suspects in the news. Journal of Communication, 49, 46-60.

Oliver, M. B., \& Fonash, D. (2002). Race and crime in the news: Whites' identification and misidentification of violent and nonviolent criminal suspects. Media Psychology, 4, 137156.

Payne, K. B., Lambert, A. J., \& Jacoby, L. L. (2002). Beat laid plans: Effects of goal on accessibility bias and cognitive control in race-based misperceptions of weapons. Journal of Experimental Social Psychology, 38, 384-396.

Payne, K. B., Shimizu, Y., \& Jacoby, L. L. (2005). Mental control and visual illusions: Toward explaining race-based weapon misidentifications. Journal of Experimental Social Psychology, 41, 36-47.

Reyna, V. F., \& Brainerd, C. J. (1995). Fuzzy-trace theory: An interim synthesis. Learning and Individual Differences, 7, 1-75.

Rodin, M. J. (1987). Who is memorable to whom: A study of cognitive disregard. Social Cognition, 5, 144-165.

Sagar, H. A., \& Schofield, J. W. (1980). Racial and behavioral cues in Black and White children’s perceptions of ambiguously aggressive acts. Journal of Personality and Social Psychology, 39, 590-598.

Scheck, B., Neufeld, P., \& Dwyer, J. (2000). Actual Innocence. New York: Random House Secord, P. F. (1959). Stereotyping and favorableness in the perception of the Negro face. The Journal of Abnormal Social Psychology, 59, 309-314. 
Secord, P. F., Bevan, W., \& Katz, B. (1956). The Negro stereotype and perceptual accentuation. The Journal of Abnormal Social Psychology, 53, 78-83.

Slater, A., \& Quinn, P. C. (2001). Face recognition in the newborn infant. Infant and Child Development, 10, 21-24.

Sporer, S. L. (1992). Post-dicting eyewitness accuracy: Confidence, decision-time, and person descriptions of choosers and non-choosers. European Journal of Social Psychology, 22, 157-180.

Sporer, S. L. (2001). Recognizing faces of other ethnic groups: An integration of theories. Psychology, Public Policy, and Law, 7, 36-97.

Smith, S. M., Stinson, V., \& Prosser, M. A. (2004). Do they all look alike? An exploration of decision-making strategies in cross-race facial identifications. Canadian Journal of Behavioral Science, 36, 146-154.

Tuckey, M. R., \& Brewer, N. (2003). The influence of schemas, stimulus ambiguity, and interview schedule on eyewitness memory over time. Journal of Experimental Psychology: Applied, 9, 101-118.

Ward, L. M. (1982). Determinants of attention to local and global features of visual forms. Journal of Experimental Psychology: Human Perception and Performance, 8, 562-581.

Wells, G. L. (1984). The psychology of lineup identifications. Journal of Applied Social Psychology, 14, 89-103.

Wells, G. L., Memon, A., \& Penrod, S. D. (2006). Eyewitness evidence: Improving its probative value. Psychological Science in the Public Interest, 7, 45-75. 
Wells, G. L, \& Murray, D. M. (1984). Eyewitness confidence. In G.L. Wells \& E.F. Loftus (Eds.), Eyewitness testimony: Psychological perspectives (pp. 155-170). New York: Cambridge University Press. 


\section{APPENDIX}

Table 1. Accuracy rate of identifications overall and broken out by accuracy-type (positive i.e., made a face identification versus negative i.e., choose 'not present'). Overall accuracy is presented as: the number of accurate identifications made/ total identifications made (positive and negative). Accuracy-types are presented as: the number of correct identifications made for each type/ total number of correct identifications made. Results are shown as a function of actor-type, individual prejudice, and level of processing.

\section{Actor-Type}

$\underline{\text { Stereotypical }}$

High Prejudice Low Prejudice $\quad$ High Prejudice Low Prejudice

\section{$\underline{\text { Local Processors }}$}

$\begin{array}{llll}\text { Overall Accuracy } & 1 / 4(25 \%) & 0 / 2(0 \%) & 0 / 4(0 \%)\end{array} 6 / 7(86 \%)$

Correct Positive IDs $1(100 \%) \quad 0(0 \%) \quad 0(0 \%) \quad 4(67 \%)$

$\begin{array}{lll}\text { Correct Negative IDs } 0(0 \%) & 0(0 \%) & 0(0 \%)\end{array}$

Global Processors

Overall Accuracy $\quad 4 / 11(36 \%) \quad 2 / 10(20 \%) \quad 3 / 9(33 \%) \quad 2 / 12(17 \%)$

Correct Positive IDs $\quad 0(0 \%) \quad 1(50 \%) \quad 2(66 \%) \quad 2(100 \%)$

Correct Negative IDs $4(100 \%) \quad 1(50 \%) \quad 1(33 \%) \quad 0(0 \%)$

Note. Correct positive/negative IDs are presented as a percent of correct IDs overall. 


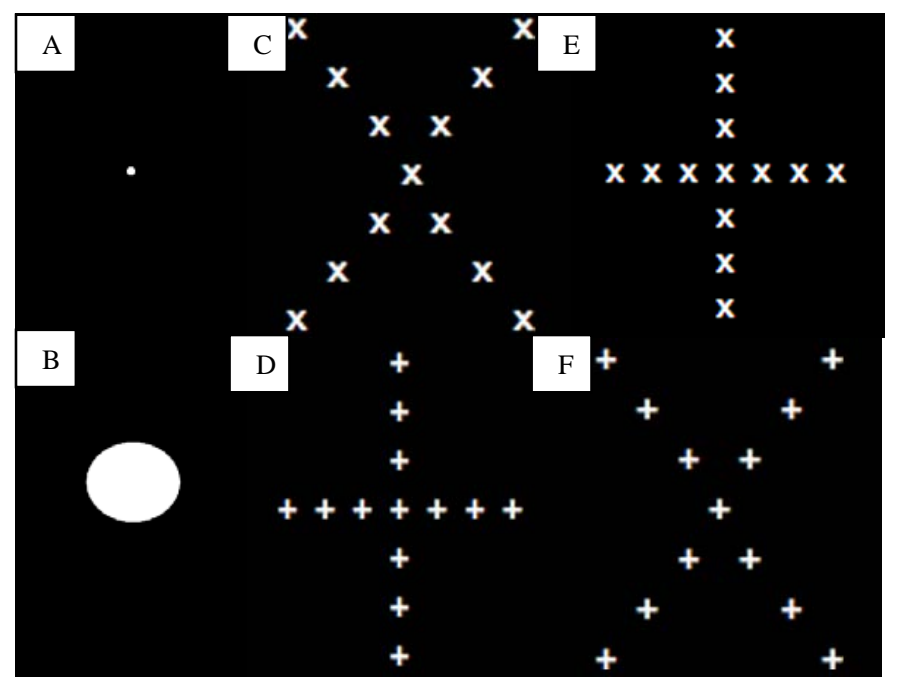

Figure 1. Processing Focus-Type Stimuli

A. The small circle-indicator directing participants to categorize the small shape in the presented symbol. B. The large circle-indicator directing participants to categorize the big shape in the presented symbol. C. and D. The large and small shapes of these stimuli are the same; therefore, they are considered consistent symbols. E. and F. The large and small shapes of these stimuli are different; therefore they are considered inconsistent symbols. 


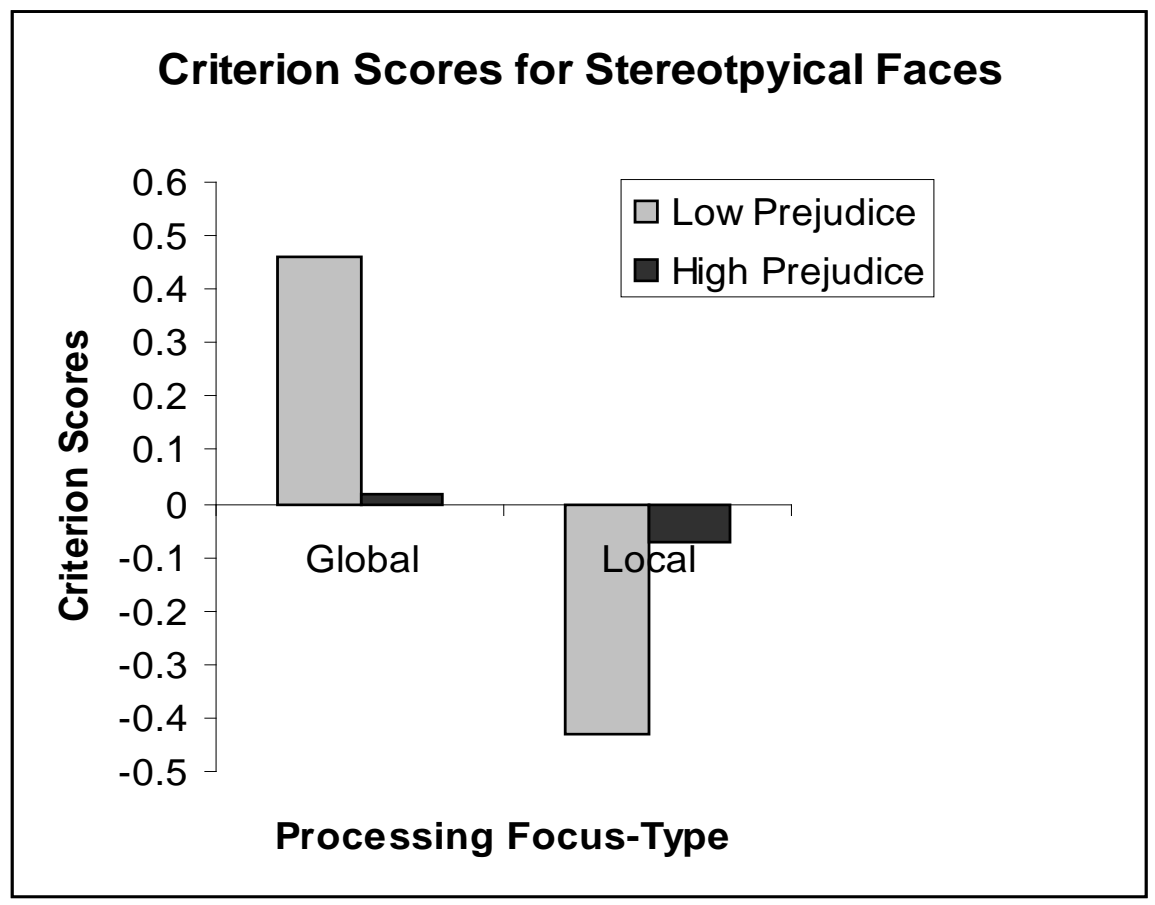

Figure 2. Experiment 1

Criterion scores used when recognizing stereotypical Black faces as a function of processing focus-type and prejudice level. 


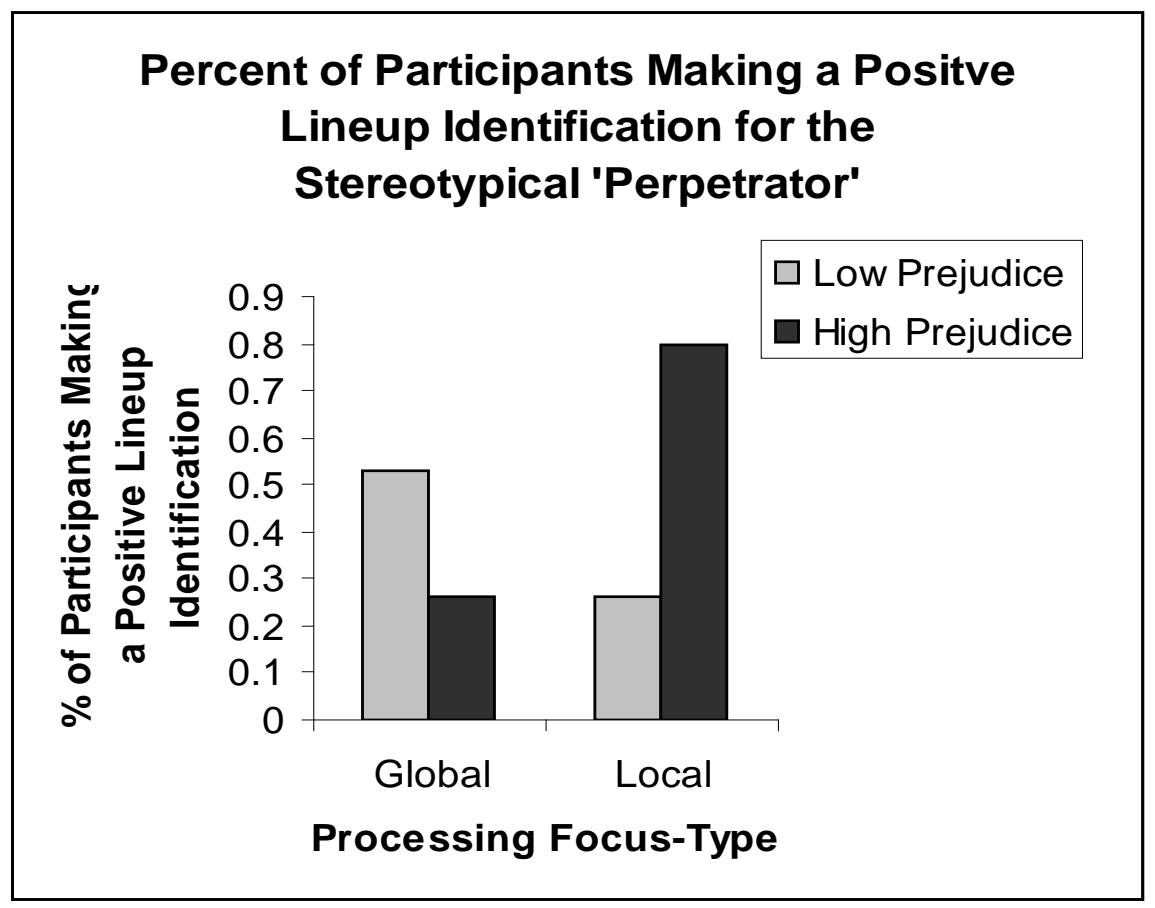

Figure 3. Experiment 2 Prediction 1

Percent of participants making a positive lineup identification (i.e., selecting any face) after witnessing the stereotypical Black 'perpetrator' commit the crime. Results are presented as a function of processing focus-type and prejudice level. 


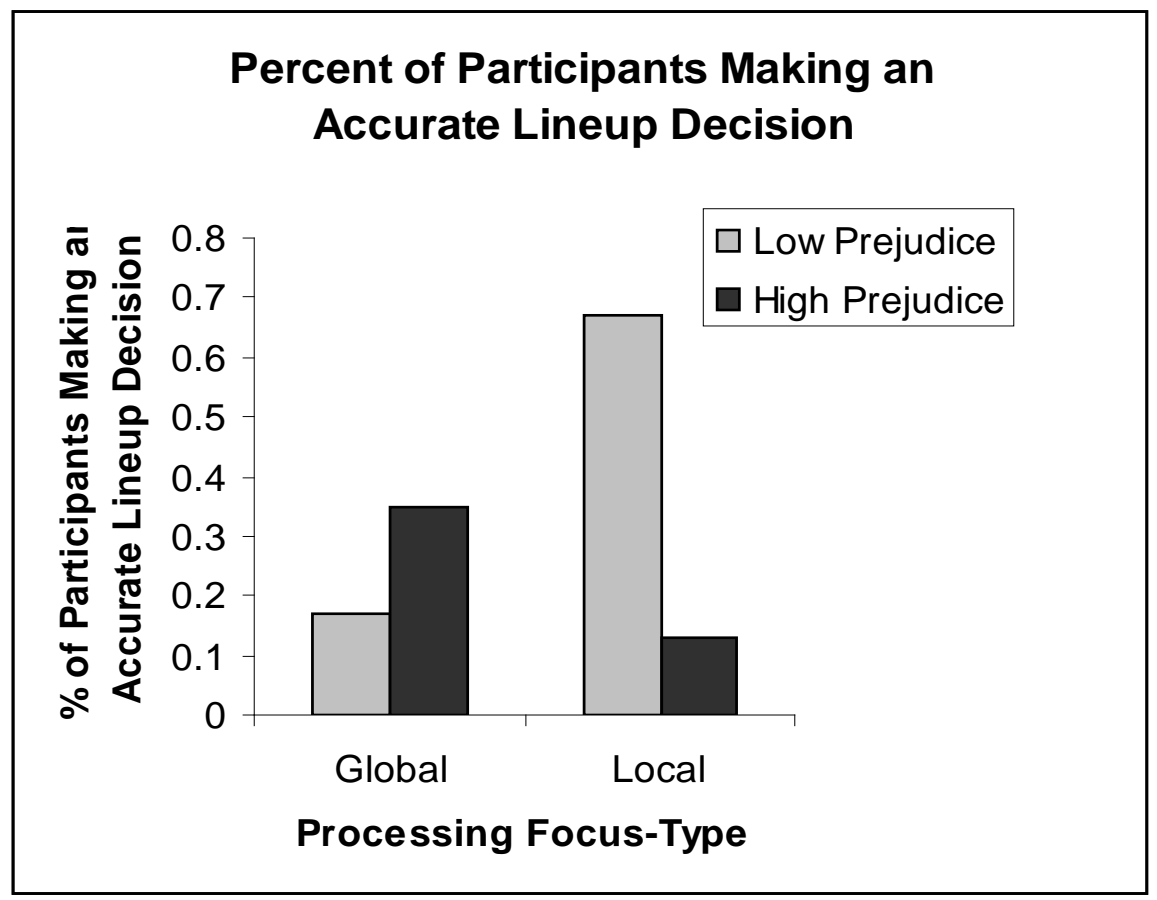

Figure 4. Experiment 2 Prediction 2

Percent of participants making an accurate lineup decision after witnessing either Black 'perpetrator' commit the crime. Results are presented as a function of processing focus-type and prejudice level. 


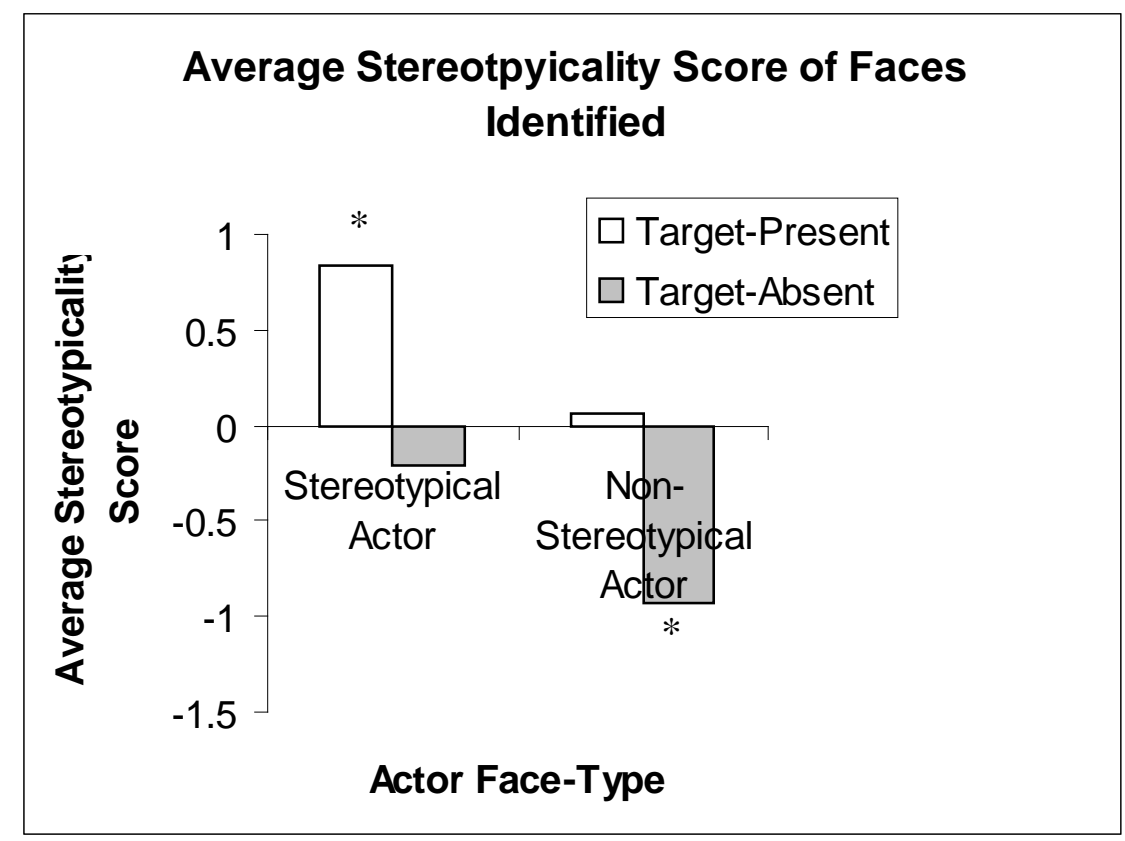

Figure 5. Experiment 2 Prediction 3

The average stereotypicality score of faces identified as a function of actor-type and lineup-type. Note. ${ }^{*} p<.05$ 


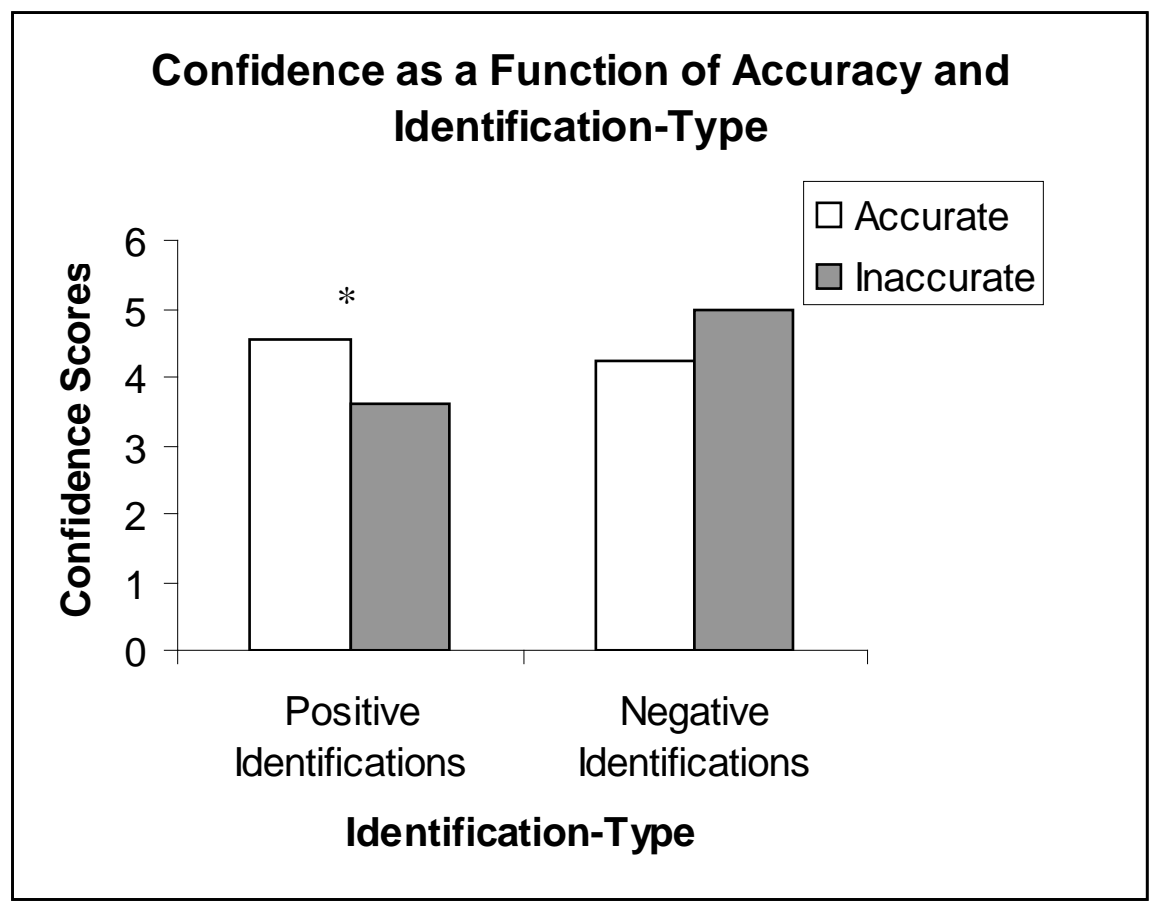

Figure 6. Experiment 2 Prediction 4a

Confidence scores reported as a function of accuracy and identification-type. Note. ${ }^{*} p<.05$ 


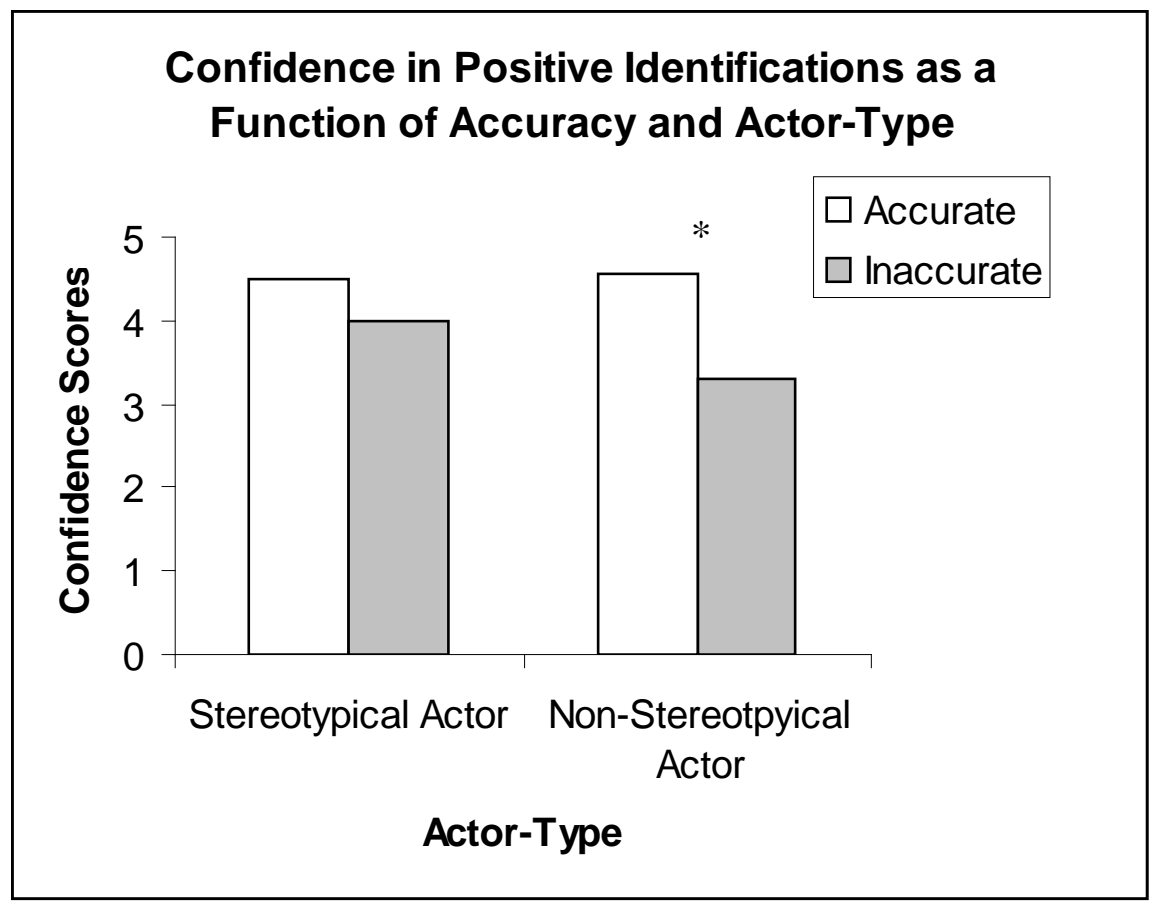

Figure 7. Experiment 2 Prediction 4b

Confidence scores reported following positive identifications as a function of accuracy and actor-type. Note. ${ }^{*} p<.05$ 